\title{
EPÍLOGO \\ ¿EN QUÉ HA FALLADO BARCELONA?
}

HORACIO CAPEL ${ }^{1}$

Las profundas transformaciones que ha experimentado Barcelona durante las últimas tres décadas la han convertido en objeto repetido de estudio. En los últimos años la experiencia urbana barcelonesa ha sido también atentamente observada en Lisboa, tal como señala Margarida Queirós en la introducción del presente número de Finisterra. En ella se alude asimismo al prestigio de la experiencia de Barcelona y al eco de algunas de las políticas que se han aplicado: la construcción de espacios de calidad, la apertura al mar, el papel asignado a la cultura, la inversión pública en la ciudad, la proyección de la imagen internacional y su función para atraer inversiones internacionales, el papel de la nueva arquitectura, y otros. Por eso mismo, se miran también hoy atentamente las limitaciones de dicha experiencia barcelonesa.

La pregunta “¿En qué ha fallado Barcelona?”, podría hacerse mejor de una forma impersonal: “¿Qué se ha hecho mal en Barcelona?”. Pero seguramente debería dirigirse, asimismo, hacia las responsabilidades: “¿Que han hecho mal en Barcelona los políticos, los técnicos, los agentes urbanos o los ciudadanos en general?". Porque, después del éxito inicial, las críticas que se hacen hoy al llamado "modelo Barcelona" muestran que algo ha debido de hacerse mal y, por esa razón, se debe dirigir la atención hacia los protagonistas y hacia las consecuencias de las políticas aplicadas.

La invitación que me han hecho las editoras de este número de Finisterra para que redacte un artículo de conclusión o epílogo, me lleva a reflexionar sobre estas cuestiones, aprovechando para ello trabajos recientes, algunos publicados en la revista Scripta Nova y Biblio $3 \mathrm{~W}$ de la Universidad de Barcelona.

La atención que presta Finisterra a Barcelona no es la primera vez que se le dedica, y está justificada también por el hecho de que esta ciudad y Lisboa tienen rasgos geográficos similares $\mathrm{y}$, sin duda, procesos de modernización que son semejantes en muchos aspectos, como tuvimos ocasión de discutir con

Recebido: 20/10/2010. Aceite: 10/11/2010.

1 Professor Catedrático de Geografia Humana da Universidade de Barcelona.

E-mail: hcapel@ub.edu 
ocasión del Coloquio Barcelona-Lisboa durante el XXVII Encontro da Associação Portuguesa de História Económica e Social celebrado en Lisboa en $2007^{2}$. Aprovecharé la oportunidad que ahora se me brinda para tratar de avanzar en la búsqueda de una nueva forma de realizar el urbanismo y la ordenación territorial, a partir del diálogo y la participación, continuando una reflexión ya iniciada, y que ha sido objeto de debate en el XI Coloquio Internacional de Geocrítica, que se celebró en Buenos Aires en mayo de este año ${ }^{3}$.

\section{NUMEROSOS ACIERTOS}

Desde las primeras elecciones municipales democráticas realizadas después de la Dictadura, en 1979, Barcelona ha estado gobernada por ayuntamientos de izquierdas, en una alianza de socialistas (Partit dels Socialistes de Catalunya, PSC), antiguos comunistas (Iniciativa per Catalunya, IC) y, eventualmente, republicanos nacionalistas de izquierdas (Esquerra Republicana de Catalunya, ERC). El balance que se realice ha de tener en cuenta, sobre todo a estos políticos y a los técnicos que han colaborado con ellos, como responsables de la política municipal. Aunque también deberíamos incluir en el análisis a otros agentes urbanos, como a los empresarios (grandes y pequeños, tradicionales y modernos...); asimismo al movimiento vecinal y a la misma ciudadanía, es decir, con ellos, a todos los actores urbanos: los que como habitantes de Barcelona nos movemos en el teatro de la ciudad, construido por otros. En este artículo de conclusión me limitaré a hacer algunas consideraciones sobre los aspectos positivos y sobre las insuficiencias del que fue llamado "modelo Barcelona", centrando la atención en la política municipal y, por tanto, en la actuación de políticos y técnicos.

Durante varios años la valoración de la experiencia de Barcelona fue muy positiva, y causaba admiración, al igual que el conjunto de la experiencia de transformación de España tras la recuperación de la democracia. Las medidas de reestructuración adoptadas por el gobierno socialista presidido por Felipe Gonzalez permitieron mejorar las condiciones económicas y laborales. Téngase en cuenta que la población ocupada en todo el país había pasado de 13,2 millones de personas en 1974 a 11 millones en 1984, y que la tasa de paro, que era del 4 por ciento en 1975, ascendió a 14,3 por ciento en 1981 y al 21 por ciento en 1984. Las medidas económicas gubernamentales, y las ayudas recibidas tras la entrada de España en la Unión Europea en 1986, permitieron mejorar la situación, aumentando la población ocupada, que llegó a ser de 16,1 millones en 2001. En el campo del urbanismo, el gobierno del Estado adoptó igualmente

2 Véase el número extraordinario de Scripta Nova dedicado a "Globalización y modernización urbana: Lisboa y Barcelona" (1 de agosto de 2009, no $296<$ http://www.ub.es/geocrit/sn/sn-296/sn296.htm>).

3 Número extraordinario de Scripta Nova, vol. XIV, no 331, 1 de agosto 2010, <http://www. ub.es/geocrit/sn/sn-331/sn-331.htm>; introducción al Coloquio en Capel 2010 a y b. 
medidas que impulsaron las actuaciones para la renovación de los centros históricos y la recualificación de las periferias urbanas.

En Barcelona, como en Madrid y otras ciudades españolas, los años 1980 fueron igualmente de gran dinamismo y de soluciones imaginativas, impulsadas muchas veces por el movimiento vecinal, bien activo y organizado en aquellos años, y por los ayuntamientos democráticos, a los que se incorporaron técnicos bien preparados y con sensibilidad ante las reivindicaciones populares. En el caso de Madrid, se ha recordado la importante presencia de las asociaciones vecinales en la iniciativa de Remodelación de Barrios y en la elaboración de los Programas de Acción Inmediata, así como su influencia en la orientación del planeamiento, de la gestión municipal $\mathrm{y}$, en definitiva en la transformación de la ciudad: "una orientación fundamentalmente ética y sensible a los aspectos sociales de las carencias"4.

En el caso de Barcelona, las actuaciones de mejora urbana fueron en la misma dirección y dieron un gran prestigio a esta ciudad, hasta el punto de que se pudo hablar de un "modelo Barcelona" que contribuyeron activamente a difundir los mismos técnicos y políticos barceloneses 5 . De manera general, la actuación de los sucesivos gobiernos municipales desde 1979 ha hecho a Barcelona más habitable y más atractiva, ha conseguido una buena imagen internacional de la ciudad, ha aumentado la dotación cultural así como los espacios públicos. Deben ponerse igualmente en el haber del Ayuntamiento el esfuerzo por mejorar la periferia, la erradicación final del barraquismo, la recuperación de los interiores de manzanas del Ensanche para mejorar la dotación de áreas verdes en ese sector, la creación de jardines, las áreas reservadas para que los vecinos puedan estacionar en el barrio, o la limitación del uso de automóviles privados ensanchando las aceras y disminuyendo el área de circulación para, como ahora se dice, "pacificar el tráfico".

Algunas de las actuaciones fueron especialmente destacadas. Entre ellas, la intervención en el centro histórico de Barcelona y las estrategias de rehabilitación urbana, las operaciones para la mejora de los barrios periféricos populares, la realización de planes sectoriales integrados en un proyecto de transformación amplia, o la creación de nuevas centralidades ${ }^{6}$. Numerosos estudios han valorado positivamente las actuaciones en transporte público realizadas en Barcelona y en el Area Metropolitana, señalando la eficiencia del servicio, su coste relativamente bajo para los usuarios, y la integración de tarifas, aunque se hayan señalado, asimismo, déficits en la planificación conjunta del territorio y del transporte metropolitano (Cebollada y Avellaneda, 2008, Cebollada y Miralles 2010 (en este número).

4 Sobre las transformaciones en Madrid debe consultarse la obra dirigida por Ramón López de Lucio 1999; la frase citada, en el prólogo de Fernando de Terán p. 12.

5 Borja 1995; sobre el eco de este modelo en diferentes países, Marshall 2000 y 2004.

6 Los rasgos esenciales de las transformaciones urbanísticas han sido bien presentadas por Joan Busquets, que fue uno de sus protagonistas (Busquets, 2004, cap. IX). 
Durante este periodo, además, el ayuntamiento de Barcelona expresó su voluntad de realizar una política de izquierdas. Lo cual se reflejó en algunas de las medidas tomadas; por ejemplo en una decidida política de inversión en los barrios populares periféricos; o en la intención de realojar en el mismo barrio a los afectados por las intervenciones de remodelación en Ciutat Vella, voluntad que fue explícitamente formulada y aplicada a aquellos que eran propietarios de sus viviendas o tenían contratos de arrendamiento (lo que pudo dejar fuera a quienes carecían de algún tipo de documento legal, razón por la que dichas intervenciones fueron también criticadas).

No son pocos los autores que recorriendo Barcelona ven en la ciudad el éxito de las políticas urbanas, y perciben que se supo "hacer ciudad" (Queirós, 2009). Sin duda tienen razón en su apreciación, ya que han sido numerosos los aciertos de la política municipal de Barcelona, en las últimas tres décadas.

\section{LAS VOCES CRÍTICAS}

Sin embargo, desde fines de los años 1980 empezaron a oirse voces críticas sobre las políticas municipales, en relación con diversos frentes de actuación. Uno de ellos, las mismas intervenciones en el centro histórico de Barcelona (López Sánchez, 1986; Heeren, 2002), o las políticas para facilitar la construcción de vivienda social, consideradas insuficientes. Las críticas aumentaron durante la década de 1990 y, especialmente, en relación con la celebración del Forum de las Culturas en 2004. En algunos de los actos que el mismo Forum organizó los participantes hablaron ya abiertamente del fin del consenso urbano sobre Barcelona, que se había construido en la lucha para la recuperacion de la democracia ${ }^{7}$.

Los excesos en la propaganda del llamado "modelo Barcelona" empezaron a provocar reacciones contrarias en algunos lugares, y llegaron incluso a ser motivo de irrisión. En 2002, en plena crisis económica en Argentina, un grupo de periodistas de Buenos Aires fundaron un periódico quincenal cuyo título resulta bien expresivo: "Barcelona una solución europea para los problemas de los argentinos". Su éxito fue espectacular, ya que realiza una feroz parodia de las noticias de la prensa, y todavía tiene miles de fieles lectores porteños que lo esperan en los quioscos cada quince días ${ }^{8}$.

En los años siguientes se hicieron explícitas gran número de críticas a dicho 'modelo', por parte de geógrafos, arquitectos, antropólogos, sociólogos, histo-

7 Ejemplos en Andreu Acebal (2008), con testimonios de intervenciones de Josep Ramoneda y de Jordi Borja, que advertían del riesgo de ruptura del modelo Barcelona por la fuerza de la iniciativa y los intereses privados, del urbanismo de promotores y negocios, frente a la debilidad de la administrción municipal y de la alternativa del urbanismo ciudadano y redistributivo.

8 El periódico puede consultarse en $<$ http://www.revistabarcelona.com.ar/>. He dedicado un comentario a dicho periódico en La Veu del Carrer, número correspondiente a noviembre 2010, en publicación. 
riadores y periodistas ${ }^{9}$. En los países iberoamericanos, donde la influencia de los consultores catalanes había sido muy grande, se levantaron también voces críticas que señalaron que ese proyecto de ciudad implica - como escribió Carlos B. Vainer, de una forma tal vez excesiva "la directa e inmediata apropiación de la ciudad por intereses empresariales globalizados y depende, en gran medida, de la expulsión de la política y de la eliminación del conflicto y de las condiciones del ejercicio de la ciudadanía" 10 .

Especialmente activo fue el movimiento vecinal barcelonés, que desde fines de los años 1980 había tenido un proceso de distanciamiento respecto al ayuntamiento, que, por su parte, se consideraba único exponente de la legalidad democrática y desconfiaba de dicho movimiento. El cual, a su vez, empezó a recelar del ayuntamiento por sus alianzas con el capital internacional ${ }^{11}$. Como resultado de ello se produjeron diferentes movilizaciones sociales en relación con problemas diversos, y se rompió el consenso ciudadano que había existido en la década de 1980. La Federación de Asociaciones de Vecinos de Barcelona (FAVB) y su órgano la revista La Veu del Carrer - ejemplamente dirigida por Andrés Naya y, más tarde, también por Marc Andreu - adoptaron una actitud crítica respecto al Ayuntamiento, que era un reflejo de dicho distanciamiento $^{12}$.

Esto suponía un cambio de gran trascendencia, ya que las reivindicaciones de los movimientos populares habían sido esenciales para la acción municipal. Una exposición sobre "Cuarenta años de movimiento vecinales y de acción vecinal en Madrid y Barcelona", celebrada en mayo de 2010, ha mostrado de forma clara la importancia de las movilizaciones que se realizaron ${ }^{13}$. En ella aparecen unas doscientas reividicaciones y acciones ciudadanas planteadas en ambas ciudades (100 en Barcelona y 80 en Madrid), sobre libertad y democracia, cultura e identidad de barrio, derecho de las mujeres y lucha por su reco-

9 Entre los geógrafos P. López Sánchez, 1993, Ma Dolors García Ramón y Abel Albet, 2000, Horacio Capel (2005, 2006 - en respuesta a Bohigas 2005 -, 2007 y 2009), o Antònia Casellas, 2006; arquitectos como Javier Monclús, 2003, y Montaner, 2003, y 2004 a y b, y Montaner y Fava, 2008; el antropólogo Manuel Delgado (2007); sociólogos como Mónica Degen y Marisol García, 2008; historiadores del arte como A. Cócola, 2009, o de la literatura, Joan Ramon Resina, 2008; periodistas como Marc Andreu Acebal, 2008. Recientemente se han publicado balances muy ponderados, entre los que destaca el libro de Jordi Borja, Luces y sombras del urbanismo de Barcelona, 2009.

10 Vainer, 2000 (la cita en p. 78; puede calificarse de excesiva por su falta de matiz respecto a las intervenciones decididamente neoliberales de gobiernos municipales de derechas en otras ciudades), y Arantes, 2000, en especial p. 51-58.

11 Como ejemplo del tipo de críticas tempranas que se hicieron puede verse López Sánchez, 1992 у 1993.

12 La colección completa de La Veu del Carrer puede consultarse en línea en $<\mathrm{http}: / /$ favb. cat/taxonomy_menu/2/4>

13 Se celebró en mayo de 2010 con el título Barcelona 40 Anys d'Acció Veïnal-Madrid, 40 años de Acción Vecinal, Puede verse en $<$ www.memoriaveinal.org $>$ y puede complementarse con la consulta del $\mathrm{n}^{\circ} 114$ de La Veu del Carrer <http://favb.cat/pdfs/carrer_114/carrer114.pdf $>$, y el volumen de Quaderns de Carrer, $n^{\circ} 5$ (Andreu, Fernández Naya y Prieto, 2010). 
nocimiento, gente mayor, barraquismo, vivienda, planeamiento urbano, enseñanza, deportes, sanidad, servicios públicos, movilidad, medio ambiente y sostenibilidad. En la exposición se ve que en los años 1980 los movimientos populares pusieron en marcha movimientos solidarios y fueron agentes de la construcción del tejido social, a la vez que plantearon reivindicaciones ciudadanas que serían recogidas por los gobiernos municipales democráticos de izquierdas instalados en Madrid, en Barcelona y en otras ciudades españolas. Gracias a ellas se construyeron equipamientos, se conservaron edificios significativos para la historia y la identidad de las ciudades, que han podido acoger centros cívicos o culturales, y se propuso otro modelo de desarrollo más sensible a las necesidades de los ciudadanos ${ }^{14}$. Se trata de una historia que, como se dice en la sección madrileña de la exposición antes citada, está llena

"de asambleas, de pegadas de carteles, de caminar calles y despachos; de esfuerzos y sacrificios, pero también de conquistas y superación colectiva. Una historia que da fe de la capacidad de las personas para transformar la realidad y que se ha plasmado en nuestras calles con la creación de bibliotecas, parques, centros de salud, paradas de metro... Mejoras materiales que el movimiento vecinal ha arrancado a los poderes, a la par que contribuía a la conquista y desarrollo de los derechos y reivindicaciones democráticas".

El distanciamiento entre el movimiento popular y el ayuntamiento de Barcelona, creciente en los años 1990, se reflejaría en los resultados de las elecciones municipales. El número de concejales del PSC, que había sido de 20 en 1999, bajó a 15 en 2003, y descendió todavía a 14 en 2007. El nivel de abstención fue elevado, lo que puso de manifiesto el descontento con las medidas que se había ido adoptando y la desconfianza ante los representantes políticos y los gestores municipales. Representaba una puesta en cuestión del modelo de política urbana y económica seguido por el Ayuntamiento, y dio paso a propuestas de carácter más general sobre la forma de gobernar la ciudad, con énfasis en la participación ${ }^{15}$.

Al igual que sucede cuando una formación política experimenta una disminución drástica de votos, también en el caso de Barcelona los responsables afectados asegurararon que habían entendido el mensaje de sus electores, y que iban a cambiar de política; pero, en muchos casos, frecuentemente olvidan sus buenos propósitos de forma muy rápida. Los concejos municipales que surgieron en Barcelona de las elecciones de 2003, y luego de las de 2007, trataron de

14 Sobre las acciones de la Federación Regional de las Asociaciones de Vecinos de Madrid, véase Andreu, Fernández, Naya y Prieto, 2010, p.373 y ss., y <http://aavvmadrid.org/>, y especialmente $<$ http://aavvmadrid.org/index.php/aavv/quienes_somos $>$

15 Marc Andreu, 2008 ha recordado oportunamente la importancia del movimiento vecinal en la aparición de la crítica al modelo Barcelona y recuerda que "el qüestionament del model de ciutat per part dels moviments socials i, en concret, el veïnal és a principis del segle XXI gairebé tant profund com al 1975". 
enderezar la situación poniendo énfasis en recuperar el contacto con los ciudadanos, y prometiendo un cambio de política, que pondría más énfasis en el bienestar social y la convivencia que en el urbanismo y los negocios; pero no es seguro que hayan sabido convencer a los ciudadanos de la decisión inequívoca para ello.

\section{CRECIMIENTO ECONÓMICO Y NECESIDADES CIUDADANAS}

La idea de que solo el crecimiento económico puede asegurar el bienestar social afectó seguramente a las prioridades establecidas. En Barcelona se pensó sobre todo en el marquéting urbano, en el mercado internacional, en hacer atractiva la ciudad para la inversión de capitales. Pero el Ayuntamiento no siempre supo aunar la preocupación por las políticas de desarrollo económico y de promoción económica, de difusión de la imagen, o la puesta en marcha de megaeventos deportivos y culturales (como los Juegos Olímpicos y el Forum), por un lado, y la provisión de servicios para los habitantes de la ciudad, por otro.

A ello se unió otro aspecto importante de la política urbana desde los años 1980, el énfasis en la colaboración público-privada, que se ha valorado como decisiva en las transformaciones de Barcelona ${ }^{16}$. Sin duda dicha política generó éxitos, en relación con los objetivos planteados. Pero la colaboración con distintos agentes urbanos privados, y especialmente con los agentes inmobiliarios, no siempre ha sido bien controlada o gestionada, y ha podido tener también consecuencias negativas ${ }^{17}$.

El modelo de desarrollo urbanístico apoyado en la colaboración entre el sector público y privado no es históricamente desconocido en España, pero se intensificó en los años 1980 y 90 por la influencia de las ideas neoliberales difundidas desde el mundo anglonorteamericano, que acentuaron también las consecuencias negativas para la igualdad social y para el medioambiente ${ }^{18}$. Se ha señalado que es un modelo impropio de un gobierno de izquierdas, en el que a veces el ayuntamiento prepara suelo e infraestructuras y los empresarios privados construyen los edificios y obtienen los beneficios. En todo caso, esas políticas de concertación se han de basar en una visión clara por parte del poder municipal, en un liderazgo decidido, con la más absoluta honradez, en una posición de fuerza frente a los agentes privados, lo que no es seguro que haya existido siempre en Barcelona. Frente a la valoración del liderazgo municipal en los años 1980, hoy

16 Por ejemplo, por Casellas et al., 2010.

17 Denunciadas repetidamente por La Veu del Carrer, órgano de la Federación de Asociaciones de Vecinos de Barcelona $<$ http://favb.cat/taxonomy_menu/2/4> y por diversos autores (como los citados en nota 12).

18 Véase, por ejemplo, Casellas, 2007, que alude en ese sentido a las críticas que se han hecho a esas políticas en Estados Unidos, por ejemplo, por parte de autores como el historiador urbano Marc Levine en sus análisis sobre Baltimore. 
se repite que ha faltado tanto éste como la capacidad técnica para gobernar la ciudad, especialmente a partir de los años 1990 (Clarós i Ferret, 2007).

El énfasis en la cooperación público-privada, alimentada por el ambiente neoliberal que afectaba incluso al pensamiento de izquierdas, podía llevar a valorar la externalización, la flexibilización, el llamado empresarialismo municipal. La descalificación de la gestión pública, tenía que ver también con dicho ambiente neoliberal, agravado a veces en Cataluña por el sentimiento nacionalista que llevaba a descalificar la administración pública y la legislación estatal; lo que, en los años 1980, se debía, en ocasiones, al hecho de que se salía de un Estado autoritario y, en otras, era pura y simplemente rechazo del Estado y desconfianza en la gestión pública y en los funcionarios públicos, totalmente injustificada en la mayor parte de los casos. A lo cual se unía el énfasis en la eficiencia $\mathrm{y}$, junto a ello, la tendencia a tratar a los habitantes del municipio como clientes, en lugar de como ciudadanos.

El clima intelectual barcelonés facilitaba la apertura a las ideas exteriores, y llevaba a mirar atentamente lo que sucedía en otras ciudades. Políticas urbanas que se habían generado fuera se aplicaron tempranamente en Barcelona. Como, por ejemplo, la realización de planes estratégicos (Ganau y Mallarach, 2003). Las declaraciones sobre los objetivos y los propósitos de estos planes son atractivas, ya que muestran deseo de mejorar la ciudad y señalan los objetivos a alcanzar, aunque a veces no pasen de ser simple retórica, por la dificultad para gestionar y aplicar los consensos.

Esa misma apertura al exterior llevó a poner énfasis también en la importancia de los procesos de cambio hacia la ciudad postindustrial, en el nuevo papel de la terciarización y en la cruda realidad de la competencia entre ciudades. No podemos criticar la carrera de las ciudades que compiten para situarse en la escena mundial y para atraer el capital internacional, que es siempre es útil, y a veces indispensable, para el crecimiento económico. Lo que se critica es la forma como se ha hecho, y, concretamente en el caso de Barcelona, como ha sido realizado por ayuntamientos de izquierdas.

El éxito de los Juegos Olímpicos de Barcelona en 1992, y las actuaciones urbanas que se realizaron en la ciudad con ocasión de ellos, han sido mirados atentamente por otras ciudades que los organizaron más tarde; y lo son ahora por Rio de Janeiro, que prepara sus Olimpiadas para 2016. Sin duda, los Juegos constituyeron una oportunidad para la realización de fuertes inversiones públicas estatales y para transformaciones urbanas de gran importancia. Pero, frente a las valoraciones entusiastas que, generalmente, se hicieron en su momento ${ }^{19}$, existen también hoy nuevos balances críticos de la experiencia, que pueden ser útiles con vistas a facilitar criterios para otras ciudades ${ }^{20}$.

19 Hubo también disensos, como muestra el trabajo de López Sánchez, 1991.

20 Como se ha hecho en el número 895 de la revista Biblio $3 W$ dedicado a "Barcelona 1992 Rio de Janeiro 2016: Juegos Olímpicos y movimientos populares", que incluye un total de 25 artículos (Oliveira, Capel, Barbosa y Zaar, coords. y eds., 2010). 
Ha sido también muy valorada la construcción de infraestructuras que tratan de facilitar la realización de congresos o grandes actividades culturales. La posición internacional se refleja en la elección de Barcelona para reuniones internacionales y su conversión en sede de agencias internacionales, como la de la Unión por el Mediterráneo, la oficina de la Organización Mundial de la Salud y otras.

La mejora de la imagen internacional de Barcelona, el incremento de su atractivo cultural y el aumento del equipamiento hotelero han tenido consecuencias en la ciudad. Barcelona se ha convertido en un destino destacado, y un lugar emblemático del ocio a escala mundializada, especialmente a partir de los Juegos Olímpicos de 1992. La cifra de turistas que visita la ciudad se ha incrementado de manera espectacular.

El efecto positivo del turismo sobre la economía de la ciudad es indudable. Pero no deja tener asimismo consecuencias negativas: la oferta de vuelos baratos multiplica los viajes de corta duración para el consumo de alcohol o la fiesta nocturna, y provoca congestión en las áreas centrales e irritación de los residentes. Al mismo tiempo, se va haciendo borrosa la distinción entre residentes y no residentes, dado que hay nuevas figuras humanas presentes en la ciudad y que son a la vez lo uno y lo otro; son visitantes, pero residen en la ciudad un tiempo más largo que el turista tradicional y mantienen otro tipo de relaciones con ella (Quaglieri \& Russo, 2010; véase tamién Casellas, Pallarés y Dot Jutglá, 2010 (en este número)).

Sin duda muchas de las iniciativas tomadas en Barcelona son dignas de examen, ya que van en una dirección que hace frente a las nuevas situaciones que se plantean en las ciudades y en la economía mundial. Pero también deben serlo las críticas que crecientemente se han ido haciendo.

Porque no todo se ha hecho bien. Que la carrera para situarse en la escena internacional no tuviera en cuenta necesidades más urgentes de los ciudadanos, que los recursos, siempre escasos, se aplicaran a inversiones que se consideraron prioritarias por su repercusión internacional (Forum...) en lugar de a otras más sociales y necesarias para los ciudadanos, debe ser motivo de reflexión. Necesidades vivamente sentidas, como la provisión de vivienda, la educación, la convivencia o la cohesión social, no han sido suficientemente atendidas, según han manifestado numerosos observadores ${ }^{21}$.

A pesar de los esfuerzos que se realizaron en los años 1980 para recualificar la periferia sigue habiendo diversas Barcelonas, que hoy todavía parecen distanciarse más aún como consecuencia de la crisis económica. Algunos visitantes han percibido esa disociación, la existencia de varias Barcelonas y de varios "modelos Barcelona", varios procesos de fragmentación y degradación, como resultado de la intensa evolución reciente y de la actuación de los procesos de globalización, y de enfrentamientos populares a las tendencias de mer-

21 Por ejemplo, Clarós i Ferret, 2007, Borja, 2009. 
cantilización de la ciudad (Limonad. 2005, 2006 y 2007). La actual crisis económica ha contribuido a agravar la situación, ya que la población de los barrios populares se está viendo muy afectada por la caída de los ingresos, mientras que los de mayores rentas no se ven afectados o incluso las aumentan; la diferencia entre barrios ricos y pobres ha crecido, por ello, de forma acu$\operatorname{sada}^{22}$

\section{UNA ARQUITECTURA DISCUTIBLE Y UNA ESCASA SENSIBILIDAD HISTÓRICA DE TÉCNICOS Y POLÍTICOS}

Tal vez uno de los problemas que ha habido en Barcelona sea el excesivo protagonismo de los arquitectos. A pesar de que muchos autores han ponderado la arquitectura que se ha hecho en esta ciudad, y que se ha aludido también a lo que se califica como "la integración entre la cultura arquitectónica y la identidad colectiva", es discutible el protagonismo de esa arquitectura y su calidad.

Desde el punto de vista urbanístico parece que Barcelona no saber hacer plazas. Ejemplos de actuaciones equivocadas pueden ser la plaza de las Glorias o el parque central del Poblenou ${ }^{23}$. Entre los errores urbanísticos, la urbanización progresiva de la montaña de Collserola - que solo en las últimas semanas parece que se quiere corregir -, la artificialización del litoral, la ocupación creciente de la montaña de Montjuic, y la falta de sensibilidad ante conjuntos de valor indudable, como el de barrio popular de casitas bajas de La Satalía, situado en la falda de Monjuic, alegando que eso es conveniente para la ampliación del espacio libre en dicha montaña (que, al mismo tiempo, está siendo urbanizada en otros sectores).

Se ha primado en ocasiones la arquitectura espectacular, desconectada del contexto. Se construyen edificios poco o nada integrados en un entorno que tiene, a veces, varios siglos de antigüedad. Hay muchos ejemplos de lo que no debe hacerse: la arquitectura es con frecuencia banal (el calificativo es de los mismos arquitectos) e incluso, irresponsable (por sus alardes técnicos costosos e innecesarios), muchas veces está en escaso diálogo con el entorno en que se construye (por decirlo suavemente utilizando una expresión muy cara a los arquitectos): los ejemplos de arquitectura brutalista en el centro histórico de la ciudad, o los edificios recientes de la plaza de España (el mismo hotel Plaza y la nueva comisaría "ecológica"), pueden servir para confirmarlo.

22 "La desigualdad fractura a Barcelona (C. Delgado y E. Bedmar), El País, 25 de octubre 2010, Cataluña p. 1 y 3 (con un mapa de la renta familiar media por barrios); el artículo informa de que "la renta cae un 18 por ciento en Can Peguera y sube un $3 \%$ en Tres Torres", y que "la diferencia de renta entre barrios crece el $416 \%$ ". De todas formas, hasta hace pocos años algunos estudios parecían mostrar una disminución de la segregación residencial (Martori y Hoberg, 2004).

23 Sobre éste Clarós i Ferret, 2008. 
La impresión que se tiene - y que se puede corroborar en conversaciones con los arquitectos o en sus escritos -, es que cada arquitecto piensa en su edificio de forma autónoma, en términos de normas, de materiales y de funcionamiento, sin tener en cuenta, o sin considerar suficientemente, el espacio urbano en que se levanta. La ciudad se va convirtiendo en una yuxtaposición de artefactos arquitectónicos, sin sentido del paisaje urbano en el que deben integrarse. Es lo que ocurre con el hotel Barceló Raval, de doce plantas y 38 metros de altura (que en el proyecto inicial se elevaba a 48) ${ }^{24}$, construido en la Rambla Nova del Raval; o con actuaciones próximas como la nueva Filmoteca que se inagurará en marzo de 2011. En este último edificio, que es una especie de bunker de cemento, se intenta conseguir que todo se vea "tectónico y ligeramente primitivo" 25 , una declaración que, unida a la visión de otros edificios que se han construido o se construyen en el Raval y en el sector del Gótic, suscita dudas sobre si ese es el tipo de construcción apropiado para un centro histórico urbano.

Muchas veces se ha tratado de forma poco cuidadosa Ciutat Vella, un área que, en su parte más antigua, tiene dos mil años de antigüedad. Ha habido ausencia de un planteamiento global, y a veces se ha puesto énfasis en una intervención puramente arquitectónica descontextualizada del ambiente en que se levanta. Lo mismo sucede en otras partes de la ciudad, como en el Ensanche, donde, a pesar de un plan de protección, encuentra unos edificios que parecen buscar más el lucimiento del autor que la creación de un paisaje bello y agradable. Destruir el patrimonio histórico, borrar las huellas del pasado es un gran error. Las ciudades sin memoria pierden su identidad. Esas destrucciones han provocado un malestar urbano que es perceptible y que se expresa públicamente. $\mathrm{Y}$ han dado lugar a movimientos vecinales que constituyen un factor de movilización y de integración.

La existencia de un Catálogo del Patrimonio Arquitectónico con 4.000 edificios protegidos, no ha bastado para la proteccción. Ha habido un insuficiente cuidado de dicho patrimonio y carencias en lo que se refiere al patrimonio industrial o a la vivienda popular, desigualdades en los niveles de protección (que a veces solo exige una conservación parcial o autoriza intervenciones muy agresivas y que desvirtúan el elemento catalogado), e insuficiencias en lo que se refiere a los entornos de los edificios catalogados; e incluso la descatalogación, por razones discutibles, de elementos protegidos ${ }^{26}$. No se ha tenido suficiente-

24 Forma parte de la reforma de la Illa Robadors, diseñada por el estudio Martorell-BohigasMackay <http://www.urbanity.es/foro/edificios-en-general-cat/1570-barcelona-hotel-barcelo-raval. html>

25 Según se explica en el sitio web del taller de arquitectura al realizar el proyecto ejecutivo en 2005 <http://www.plataformaarquitectura.cl/2010/05/08/en-construccion-filmoteca-de-catalunamateo-arquitectura/>

26 Entre los trabajos críticos que existen pueden citarse el Cataleg de la Destrucció del Patrimoni Arquitectónic del Centre Históric de Barcelona (1999) o los trabajos de Checa-Artasu, 2008 y de Tatjer, 2008. 
mente en cuenta que, en relación con el estudio del patrimonio, se han desarrollado en la misma ciudad metodologías específicas para elaborar criterios objetivos que permitan conocer, comprender y finalmente valorar este tipo de patrimonio arquitectónico (Caballé, 2003).

A veces, una atención casi exclusiva al patrimonio más destacado ha hecho olvidar o menospreciar el valor histórico y patrimonial de las viviendas y construcciones domésticas, que pueden tener gran interés. Por ejemplo, el que se conserva de los siglos de la edad media y moderna. En los últimos años el descubrimiento de restos arqueológicos del barrio de Ribera bajo el mercado del Borne ha llevado a que algunos insistan en su conservación y musealización, lo que ha paralizado las actuaciones para construir equipamientos en ese antiguo mercado central de la ciudad, un valioso ejemplo de construcción con estructura de hierro. Pero mientras esa batalla se libra, no se atiende suficientemente el paisaje que se conserva todavía y los restos de la ciudad de la Edad Moderna, que en algunos casos se van destruyendo sin misericordia. Y lo mismo sucede con los edificios del siglo XIX que no siempre se aprecian debidamente.

Especialmente grave ha sido la desatención al patrimonio histórico industrial, con graves destrucciones en el Raval, la Villa Olímpica, el Poblenou y en otras áreas ${ }^{27}$. No se trata solamente de una cuestión histórica y estética, sino también de identidad y memoria, de continuidad de tradiciones industriales, de enraizamiento, y de posibilidades de utilizar dicho patrimonio para las necesidades actuales ${ }^{28}$. Su destrucción, además de la pérdida de espacios de gran interés formal, dificulta la comprensión del pasado de la ciudad. Como han escrito los miembros del Grupo del Patrimonio Industrial del Forum de la Ribera del Besós, su desaparición "convierte en dificilmente inteligible la conformación de Barcelona como un gran polo urbano dinámico en la Europa contemporánea", lo que - añaden - "dificulta la construcción de una cultura ciudadana y la percepción de las oportunidades colectivas de la metrópolis y del país de cara al siglo XXI" (Clarós, Estrada, Tatjer, Roca, i Vilanova, 2005 - Presentació).

A veces, recintos fabriles aparentemente 'obsoletos' contenían talleres e industrias competitivas, que quedaron afectadas por la calificación urbanística. También podían servir para albergar a artistas que encontraban en las amplias naves industriales espacios adecuados para sus actividades. Que haya creadores que emigran a otras ciudades europeas por causa de la destrucción de esos espacios industriales es lamentable, y podría haberse evitado con una adecuada política urbanística. Un reciente artículo de la revista Barcelona Metrópolis, editada por el Ayuntamiento, reconoce que varios artistas catalanes se han mudado

27 Sobre las destrucciones en el casco antiguo, véase Veïns en defensa de Ciutat Vella $<$ http:// vdbv-defensemelpatrimoni.blogspot.com/>; sobre el sector donde ahora se levanta la Villa Olímpica, Caballé, 2010; sobre Poblenou, las referencias que se dan en las notas siguientes.

28 Véase los estudios del Grupo de Patrimonio del Forum de la Ribera del Besós, y en especial los artículos publicados en Biblio $3 W$ (sobre todo los $\mathrm{n}^{\circ} 580,581$ y 598). 
a Berlín por ese motivo, y afirma que "quizás el fallo mayor fue permitir que los grandes logros fueran mermando la capacidad de autocrítica y dejaran prevalecer un cierto autoritarismo". Vale la pena reproducir la idea general de este trabajo, que parece expresar el desencanto de muchos autores sobre lo que suceden en Barcelona:

"Acaso ha llegado el momento de abandonar las tendencias globalizadas y la política de los grandes nombres, y de apostar por la especificidad y la peculiaridad. Barcelona debería desempolvar aquella capacidad de reinventarse que la caracterizó en la época preolímpica" Bosco, 2010.

Los trabajos sobre legado industrial e innovación realizados en 2003 y 2004 por el movimiento ciudadano, apoyado por un cierto número de profesionales $\mathrm{y}$ académicos, condujeron a una reflexión sobre las políticas que debían ponerse en marcha para "conciliar la preservación del patrimonio histórico y de la memoria, el desarrollo económico y la cohesión social". Lo cual dio lugar a la propuesta de un Plan Integral del Patrimonio Industrial de Barcelona con objetivos muy precisos:

"conseguir la recuperación, conservación y estudio del legado documental; mantener y hacer accesible el patrimonio físico de la ciudad fabril de los dos últimos siglos; conservar la diversidad de usos productivos en la ciudad; conectar la tradición industrial - considerada en si misma un patrimonio - con la educación y transmissión del conocimiento; y, finalmente, mostrar y difundir los impactos de la metamorfosis del mundo productivo en todos los aspectos de la vida ciudadana" Clarós, Estrada, Tatjer, Roca, Vilanova, $2005^{29}$.

Un ejemplo especialmente significativo es la actuación municipal en el conjunto fabril de Can Ricart en Poblenou, una de les piezas más destacadas del patrimonio industrial que quedan en Barcelona, proyectado en 1853 por el arquitecto y académico Josep Oriol Bernadet y en el que intervino también Josep Fontseré i Mestre (Tatjer, 2005) ${ }^{30}$.

Frente a las destrucciones que se han realizado en Poblenou, la defensa de la antigua fábrica textil de Can Ricart se convirtió en emblemática. El proyecto aprobado por el Ayuntamiento suponía la destrucción de la mayor parte del recinto, conservando solo algunos fragmentos disperso. Frente a ello, el estudio patrimonial realizado por Mercedes Tatjer y Marta Urbiola (2005) demostró la importancia de la conservación completa, porque ese espacio ofrecía una oportunidad

29 El plan alternativo - y que trata de complementar el oficial que existía - fue elaborado con la activa participación de estos autores (agrupados en el Grupo de Patrimonio Industrial del Foro de la Ribera del Besós) de forma totalmente generosa y desinteresada.

30 Sobre el valor de la rehabilitación y uso del patrimonio histórico industrial, Capel, 1996. El caso de Barcelona muestra que la defensa del patrimonio industrial es una de las formas de oposición política y de desarrollo del civismo democrático (Checa Artasu, 2007). 
excepcional para "crear un nuevo estilo de hacer ciudad", ya que era "una pieza clave de un área de nueva centralidad culturalmente arraigada, económicamente dinámica y socialmente creativa, de atractivo indudable para los habitantes locales y para los visitantes". Consideraron, además, que el mantenimiento de dicho conjunto patrimonial era "condición previa pera conseguir una amalgama entre nuevas actividades y las ya existentes, y entre actividades productivas, servicios y usos culturales capaz de generar una polaridad urbana en el corazón del distrito de nuevas actividades industriales consideradas en el 22@”. Mostraron que Can Ricart era un documento histórico de gran valor para la historia industrial barcelonesa y catalana, pieza importante para articular el conjunto del patrimonio industrial del Poblenou, y para consevar la memoria y la escala de un sector que fue calificado como el Manchester catalán; también hicieron patente que dicho edificio, al igual que otros que ya habían sido derribados o estaban amenazados, poseía un gran potencial como espacio de mezcla de usos productivos culturales, educativos, de innovación y de difusión, a partir de empresas ya existentes y de otras nuevas industriales y terciarias, tal como había sucedido con algún otro (como es el caso del llamado conjunto de Palo Alto) ${ }^{31}$.

La importancia del caso de Can Ricart, y la atención que se le presta hoy en España e internacionalmente se debe a que ha demostrado que es posible complementar y mejorar las decisiones adoptadas por la administración pública, y que el movimiento ciudadano, en colaboración con académicos y profesionales, es capaz de presentar alternativas coherentes y válidas para el urbanismo de la ciudad. El caso de Can Ricart ha sido objeto de diferentes análisis como ejemplo de los conflictos urbanísticos surgidos como resultado de decisiones adoptadas en el planeamiento urbano, y por las formas de movilización ciudadana que se han puesto en marcha ${ }^{32}$.

\section{CENTRO HISTÓRICO, GENTRIFICACIÓN E INMIGRACIÓN}

Las reformas en el centro histórico de Barcelona entre 1986 y 2000 pusieron énfasis en las aperturas de vías y de plazas, en la creación de equipamientos y espacios culturales (Museo de Arte Contemporáneo, Centro de Cultura Contemporánea de Barcelona, Convento de los Ángeles...) y buscaban una mejora general de Ciutat Vella. Pero, al mismo tiempo, la antigüedad del parque construido facilitaba que siguiera siendo un área popular y puerta de entrada de los

31 Véanse en ese sentido los estudios ya citados y otros de M. Tatjer; esos estudios han influido en que algunos autores (como Saskia Sassen) modifiquen anteriores puntos de vista; el recinto ha sido protegido legalmente como Bien Cultural de Interés Nacional, pero se está dejando degradar de forma grave y, tal vez, irreversible.

32 Por esta razón, Can Ricart es una referencia obligada en numerosos estudios recientes sobre la evolución de Barcelona, entre los que pueden señalarse el de Casellas, 2007; también en este mismo número el de Cruz Gallach y Martí-Costa, 2010. 
inmigrantes. Ante la inevitabilidad de ese proceso, pudo elaborarse luego haciendo de la necesidad virtud - otro discurso: el de la inmigración como valoración de la mezcla urbana y del multiculturalismo, especialmente reflejado en los espacios públicos.

En la década de 1980 y 90 las políticas de rehabilitación del centro, con la construcción de infraestructuras y de equipamientos culturales - con un ámbito de influencia que rebasa a veces el ámbito del barrio y de la misma ciudad -, pretendía, sin duda, detener un proceso de degradación física del espacio, y pudo contribuir a hacer atractiva Ciutat Vella para habitantes de rentas medias, es decir lo que se califica como un proceso de gentrificación o elitización. Han existido políticas urbanas que introducen procesos de reforma y mejora para adaptarlos a las necesidades de clases sociales de rentas altas, que descubren aspectos interesantes en dichas áreas, desde la centralidad a los valores históricos y simbólicos.

Son muchos los análisis críticos que se han efectuado sobre la política de intervención en el centro histórico de Barcelona. Algunos no han dudado en declarar que, en su objetivo de hacer atractivo el espacio barcelonés para el capital financiero internacional, las intervenciones urbanísticas han tratado de homogeneizar el espacio urbano, y que en el centro histórico eso ha significado el propósito de realizar, a través de intervenciones urbanísticas, "una limpieza social sin ningún tipo de consideración, yendo directamente contra los vecinos todos, auténticos dueños y protagonistas de aquel espacio" (Tabakman, 2001). Esa política habría tendido esencialmente a conseguir la gentrificación del Raval. En ese sentido, se han denunciado desalojos, expropiaciones y relocalizaciones forzosas en Ciutat Vella, que se añaden a las dificultades que aparecen en otras áreas de la ciudad, con actitudes discriminatorias e incluso xenófobas.

Otros estudios han destacado que las transformaciones en el centro histórico de Barcelona como resultado de las reformas urbanas en el periodo 1986-2000, han dado lugar a nuevos discursos sobre dicho espacio. Pero si el proceso de gentrificación estuvo en el ánimo del Ayuntamiento, solo ha tenido lugar en algunos escasos lugares ${ }^{33}$. Seguramente, debido al hecho de que "el discurso del proyecto urbano aplicado a la reforma urbana se ha limitado al esponjamiento y a la decoración de los huecos". En todo caso, Ciutat Vella se ha mantenido en buena parte como un área popular ${ }^{34}$.

Las actuaciones de realojamiento de la población afectada por las reformas emprendidas en Ciutat Vella no siempre se gestionaron bien, y en ocasiones no fueron acompañadas de un equipamiento adecuado. No hubo un adecuado pro-

33 Vease los diferentes trabajos de Sargatal, 2001, 2002, 2003 y 2009; en el último ha realizado un examen de las opiniones favorables a las intervenciones realizadas en el centro histórico, y de las críticas, situándose en el grupo de las últimas, con algunos matices; también Ter-Minsassian, 2009 a y b. Sobre el atractivo del sector para los estudiantes universitarios, Russo y Capel-Tatjer, 2007. La creación del MACBA y sus consecuencias sobre el Raval en Cócola Gant, 2009.

34 Como muestra el análisis estadístico realizado por Fiori, 2010. 
ceso de diálogo, participación ni concertación; tampoco se estudiaron suficientemente los criterios para el realojamiento, o las consecuencias para aquellos que no podrían beneficiarse del reacomodo en el mismo barrio; ni se tuvieron en cuenta las consecuencias que podrían tener los desalojos y realojamientos en las redes sociales existentes, que se vieron seriamente afectadas. Es cierto que se han realizado operaciones de vivienda social y de vivienda libre, pero han sido insuficientes y, además, su arquitectura en algunos casos totalmente equivocada (como en el de las operaciones del críticamente calificado "Forat de la Vergonya", o Agujero de la Vergüenza por la amplitud de los derribos y la discutible calidad de la arquitectura construida).

Investigaciones cuidadosas han mostrado las contradicciones en las actuaciones. El análisis de los discursos intitucionales, por ejemplo los difundidos por el Ayuntamiento desde la revista Barcelona Metrópolis Mediterránea, muestran la voluntad de autolegitimación de las autoridades municipales, el abandono progresivo de la política de rehabilitación y la incapacidad para realizar una reflexión de conjunto sobre el casco antiguo (Ter-Minassian, 2009 y 2010). La coexistencia entre estrategias de gentrificación y la degradación de extensas áreas del centro muestra una incapacidad para actuar de forma coherente.

Barcelona, al igual que algunos municipios próximos, creció espectacularmente hasta fines de los años 1960, pero luego perdió población durante varios decenios $^{35}$. Aunque personas jóvenes, solteras, profesionales de elevado nivel educativo, han podido tener tendencia a valorar los espacios centrales, las familias de clase media formadas o en proceso de formación tendieron a abandonar el área central y dirigirse a otros barrios y, cada vez más, a municipios con viviendas más amplias y baratas (López Gay y Recaño Valverde, 2008).

$\mathrm{La}$ antigüedad del parque construido conservado, influiría decisivamente para que el centro histórico de Barcelona se convirtiera, otra vez, en la puerta de entrada de la nueva inmigración a la ciudad, en este caso inmigración de origen extranjero y procedente de áreas culturales muy variadas. La llegada de inmigrantes extranjeros, ha dado lugar a un fuerte proceso de crecimiento y renovación demográfica y social en el municipio de Barcelona, que ha detenido la pérdida poblacional anterior (Bayona Carrasco \& Gil Alonso, 2008).

Con la nueva llegada de inmigrantes, en este caso extranjeros, éstos han ocupado el centro antiguo, como sucedió durante el siglo XX. Muchos edificios se habían degradado por la no realización de obras durante la época de congelación de alquileres (entre los años 1920 y 1985), y se han convertido en viviendas de baja calidad. Son las que primeramente han ocupado los inmigrantes en Ciutat Vella, con gran beneficio para sus propietarios.

Algunos sectores se han convertido en claramente etnicos: paquistaníes, marroquíes, dominicanos o filipinos. La cuestión de si la concentración de inmi-

35 Entre 1981-2001 el municipio perdió 250.000 habitantes, la mayor pérdida de todos los municipios españoles, por encima de Madrid, y su área más próxima, que perdió 110.000 habitantes (Pujadas, 2009). 
grantes genera el éxodo de la población autóctona residente ha sido debatida en varias ocasiones. Algunos lo consideran un mito urbano, que se apoya en la concepción del inmigrante como una categoría social inferior y "degradante"36. Desde fines de la década de 1990 el problema de la inmigración dio lugar a debates en el centro histórico de Barcelona sobre la "degradación" y la "delincuencia" en el barrio. En 1997 se realizaron diversas asambleas de vecinos (de la Asociación de Vecinos del Casc Antic, o de la Coordinadora de Vecinos del Casc Antic), sobre los planes urbanísticos, y sobre el retraso en la ejecución del PERI, y consideraron que las mejoras urbanísticas eran más urgentes que las cuestiones de la inmigración para frenar el deterioro que vivía el barrio. Según algún estudio, la menor resistencia a los inmigrantes en Ciutat Vella tiene que ver con el dominio de la vivienda en alquiler: en otros barrios donde la propiedad domina, la llegada de inmigrantes se teme porque desvaloriza la propiedad. Asi, como ha escrito Mikel Aramburu (2001),

"La identificación del "inmigrante" como figura degradante obedece a las propiedades de su categorización social y cumple la función de chivo expiatorio de diversos "males" (la despoblación, la degradación, etc.) a los cuales les falta una explicación o una estructura narrativa que dé cuenta de su complejidad.... Sin embargo, la función de chivo expiatorio de la degradación urbana y de la huida autóctona que cumple el "inmigrante" puede convertirse con el tiempo en una profecía que se autocumple".

En general, los inmigrantes tienen facilidades para el empadronamiento, la tarjeta sanitaria y la escolarización de los hijos. Pero se plantean también tensiones en relación con la convivencia en las áreas populares y con el trabajo, lo que da lugar a conflictos, que a veces están latentes. Las cuestiones planteadas son dos. Una, los conflictos en los lugares de la vivienda; y, otra, la capacidad de la economía para absorber a todos los que quieren llegar. Sobre todo en relación con la pregunta de hasta dónde se puede llegar en la recepción de esta nueva población.

Las cuestiones de la integración de inmigrantes han sido siempre delicadas, y las siguen siendo en la Europa actual. El Grupo de Reflexión sobre el Futuro de la Unión Europea, que preside Felipe González, ha insistido en que la llegada de inmigrantes extranjeros no es un problema sino "una parte sustancial de la solución" para resolver las cuestiones del envejecimiento de la población europea, y que la demagogia anti-inmigrantes "se volverá contra los valores y los intereses de Europa". Pero también ha señalado que "hay que regular los flujos, ajustándolos a las necesidades y capacidad de integración como políticas de conjunto y aplicaciones nacionales (González, 2010). Sin duda ahí está el quid de la cuestión: cómo conseguirlo, qué cantidad de inmigración es posible para

36 El antropólogo Mikel Aramburu (2001) ha discutido ese mito de la huida de los autóctonos ante la inmigración extranjera. 
que se ajuste a las necesidades y a la capacidad de integración (Capel, 2001 y 2002). En todo caso, los problemas se plantean, y se plantearán, en los barrios populares, que es donde mayoritariamente se instalan los inmigrantes: la proporción de ellos en Sarría o en Sant Gervasi es verdaderamente reducida.

Los debates se han hecho más agudos hoy porque los inmigrantes actuales forman parte de redes transnacionales, pueden mantener contactos diarios con sus lugares de origen, o con otros, e invierten sus ganancias en su país ${ }^{37}$. Las tensiones pueden agravarse en la actual situación de crisis, con un elevado índice de paro y con una fuerte competencia por la obtención de empleos.

En el centro histórico el uso de los espacios públicos existentes no garantizan la convivencia ${ }^{38}$. El único lugar que lo garantizaría, la escuela pública para todos, está siendo abandonada por los gobiernos de izquierda, tanto el del Ayuntamiento de Barcelona como, sobre todo, el de la Generalitat. La política de conciertos con la enseñanza privada, con la canalización de recursos públicos hacia ella, contribuye a fracturar la educación básica y secundaria, y constituye un grave riesgo para la convivencia en el futuro.

\section{VI. ¿HASTA DONDE LLEGA BARCELONA?}

Es evidente que en los últimos decenios el proceso de internacionalización de la economía de Barcelona se ha ido produciendo de forma inseparable de la constitución del área metropolitana. Los trabajos de Joan-Eugeni Sánchez han puesto de manifiesto el cambio de escala en la localización de las actividades: la industria y los servicios existentes en Barcelona se han desplazado hacia los municipios próximos, y es el espacio metropolitano el que adquiere significado económico a escala internacional (Sánchez, 1992 a 2007) ${ }^{39}$. Esa evolución puede ir unida al mantenimiento e incluso refuerzo de las localizaciones centrales de servicios de dirección, que también han adquirido mayor complejidad con la aparición de centros direccionales y de nuevas centralidades ${ }^{40}$.

La gestión de toda esa estructura espacial, económica y demográfica plantea problemas, ya que necesita órganos de coordinación. Existen diversas estructuras administrativas: municipios, consejos comarcales y un área metropolitana, que, como entidad administrativa, aparece y desaparece. Y también mancomunidades de municipios para problemas concretos como energía, agua o transporte.

37 Algún trabajo sobre los inmigrantes extranjeros en Barcelona ha aludido a esas cuestiones, como Almeida, 2008, con referencia a los brasileños.

38 Véase sobre ello Magrinyà Torner y Maza Gutiérrez, 2001.

39 Sobre la organización de los nuevos espacios de la producción y consumo en el rea Metropolitana de Barcelona en relación al sistema de ciudades y las infraestructuras existentes, véase Font Arellano y Vecslir Peri, 2008; la morfogénesis del territorio metropolitano de Barcelona en Font, Llop y Vilanova, 1999; y Font et al., 2005.

40 Véase también Boixader, 2007, y Marmolejo y Stallbohm, 2008. 
Cómo gestionar todo eso, cómo hacer compatible la gestión integrada, la coordinación, la autonomía municipal y la imbricación con los niveles políticos superiores (la Comunidad Autónoma y el Estado) es un problema importante. No se sabe si Barcelona y los otros municipios tienen la voluntad política y la capacidad para lograr todo.

En los años en que Jordi Pujol era Presidente de la Generalitat defendió con gran fuerza la 'Europa de las Regiones', frente a la de los Estados que constituyeron y se integraron en la Unión Europea. Por su parte Pascual Maragall, alcalde de Barcelona, prefería hablar de la 'Europa de las Ciudades', en una estrategia política urbana enfrentada a una Generalitat de Cataluña gobernada por Convergencia i Unió. Ambos eran artificios políticos utilizados para la ocasión, porque se pudo comprobar que Maragall olvidó la Europa de las Ciudades en cuanto llegó a la presidencia de la Generalitat, mientras que la Europa de las Regiones era una estrategia para tener peso político e, incluso, un eufemismo para la construcción de una Europa diferente, con Estados más pequeños.

En todo caso, cuando se proponía la Europa de las Ciudades, Maragall pensaba, sin duda, no solo en el municipio del que era alcalde (de un centenar de kilómetros cuadrados) sino, más allá, en una entidad más amplia que se extendía a otros municipios circundantes. Un continuo conurbado con los más próximos, al que podemos denominar la aglomeración de Barcelona, que se extiende a una docena de municipios, desde Montgat y Badalona, por el norte, hasta Sant Joan Despí y Martorell, por el sur. Más allá de ellos, otros municipios poseen núcleos urbanos que, aunque discontinuos, forman parte del Área Metropolitana de Barcelona, una unidad que ha sido delimitada de formas diversas desde el punto de vista administrativo o estadístico. En la delimitación actual, engloba 36 municipios, con una superficie total de $628 \mathrm{~km}^{2}$ y unos tres millones de habitantes. Al exterior todavía se identifica una Región Metropolitana, que se extendería a 163 municipios, una superficie total de $3.234 \mathrm{~km}^{2}$ y más de 4,6 millones de habitantes ${ }^{41}$.

Los problemas de la delimitación del Área Metropolitana de Barcelona interfieren con los de la división territorial de Cataluña, y la consiguiente definición de niveles supramunicipales (comarcas y veguerías) que sustituyan a las divisiones territoriales del Estado, aprobadas en 1833. Diferentes intentos realizados desde 1936 han dado lugar a una maraña de divisiones territoriales en las que se inserta de forma diversa lo que podría calificarse de área metropolitana de Barcelona ${ }^{42}$; cuestión complicada, todavía más, con los diseños de otros mapas de competencias supramunicipales, como los relacionados con la administración

41 Casi cinco millones en la actualidad: pueden verse sobre ello los estudios socioeconómicos hechos para el Plan Territorial de la Región Metropolitana de Barcelona en la página web del Departament de Politica Teritorial i Obres Públiques de la Generalitat de Catalunya <http://www20.gencat. cat/portal/site/ptop>, y Nel·lo 2011 (en publicación).

42 Los debates y resultados de esas propuestas pueden verse en Bargueño, 2009, Mendizábal Riera, 2009, Nel·lo, 2009, Oliveras Samitier 2009, Sanclimens Solervicens, 2009. Un geógrafo y político que conoce bien el problema, no ha dudado en hablar del "barroquismo de la estructura administrativa”, del ámbito metropolitano (Nel·lo, 2011, en publicación). 
sanitaria de Cataluña, que difieren de los mapas comarcales vigentes (Casadevall, 2010), y con las áreas reales de movilidad laboral y su evolución en los últimos dos decenios ${ }^{43}$.

La institucionalización del Área Metropolitana de Barcelona y la creación de órganos administrativos para gestionar los servicios comunes ha generado problemas políticos. Los esfuerzos que desde 1953 (con el Plan de la Comarca de Barcelona) se fueron haciendo para la creación de una estructura administrativa supramunicipal que diera cuenta de la nueva realidad urbana y, finalmente, la toma de conciencia de la formación del Área Metropolitana como un espacio complejo, ha dado lugar a conflictos, y soluciones diversas ${ }^{44}$. Tras la restauración de la democracia, en general las fuerzas políticas de izquierda que eran mayoritarias en Barcelona y municipios circundantes, defendieron la existencia de la Corporación Metropolitana para el gobierno del Área Metropolitana, mientras que el gobierno de la Generalitat en manos de CiU era contrario y finalmente la disolvió, en marzo de $1987^{45}$. La paradoja es que una vez que la izquierda alcanzó el poder en la Generalitat no adoptó medidas para restaurar dicha Área y comenzó a hablar de "órganos de cooperación municipal" y de un territorio y unas instituciones "de geometría variable".

En 2003 se aprobó el Primer Plan Estratégico Metropolitano de Barcelona, con la participación de todos los ayuntamientos y más de 300 entidades, para promover procesos de transformación de dicha área en un marco de cooperación público-privada, para la gestión del terriotorio con vistas al desarrollo económico.

Finalmente la Ley $31 / 2010$ de 3 de agosto de 2010 ha acordado la creación del Área Metropolitana de Barcelona con "la voluntad de mejorar la eficiencia y eficacia de las administraciones que actúan en el territorio metropolitano, garantizando la prestación de unos servicios públicos de calidad, mediante la configuración de una administración próxima y capaz de incrementar la implicación y participación ciudadana en una realidad de continuidad urbana, densidad demográfica y características económicas y sociales que lo hagan necesario". El AMB asume las competencias que ejercen las actuales entidades metropolitanas del transporte, de servicios hidráulicos y tratamiento de residuos y la Mancomunidad de Municipios y, en materia de urbanismo, las competencias establecidas por la legislación urbanística vigente.

Sea cual sea la configuración administrativa de esa área o región metropolitana integrada, posee un conjunto de ciudades medias y pequeñas que le

43 Sobre ello véase Castañar, Gutiérrez y Vicente, 2009.

44 Monclús, 1998, Oliveira, 2010; este autor ha estudiado a partir de las noticias de la prensa, el largo proceso de institucionalización del Área Metropolitana de Barcelona y la creación de las instituciones administrativas para la gestión de ese territorio y los servicios comunes.

45 Sobre la constitución de la Corporación Metropolitana de Barcelona, y su desaparición en la década de 1980, ha sido tratada por Sastre Fulcará, 2009; también Orio Nel.lo, 2010, en publicación. 
dan un carácter policéntrico ${ }^{46}$. La ciudad de Barcelona es sin duda el núcleo central y esencial de la región metropolitana de Barcelona, pero está íntimamente unida a la docena de municipios conurbados que forman la densa aglomeración barcelonesa; un área que experimentó un fuerte crecimiento hasta finales de la década de 1960, con la construcción en núcleos compactos y el predominio de la vivienda en bloques. Posteriormente, la salida de los habitantes de Barcelona y de otras ciudades menores buscando nuevas residencias en los municipios periféricos ha sido una característica de los últimos decenios y dio lugar a un decrecimiento, paliado luego, ya lo hemos visto, por una reciente recuperación, debido a la inmigración. Como resultado de esa evolución, el peso demográfico del municipio de Barcelona se ha reducido, del 65 por ciento de la Región Metropolitana de Barcelona en 1950 al 33 por ciento en 2006 (Pujadas, 2009).

Con todo ello se ha ido configurando una nueva realidad urbana. Las personas que habitan el territorio viven en un lugar, trabajan en uno distinto, se divierten o se relacionan en otros diferentes. Las prácticas de movilidad basadas en el automóvil privado se han mantenido, a pesar de las declaraciones sobre la necesidad de una movilidad sostenible basada en el transporte publico y de las declaraciones sobre la conveniencia de una ciudad compacta, que sin embargo extiende cada vez más la urbanización de baja densidad (Miralles-Guasch, Cebollada y Requena, 2010; y Casellas, Pallarés y Dot Jutgla, 2010 (en este número)). El porcentaje de construcción de ciudad compacta ha significado solamente una reducida parte del total urbanizado.

Ha aumentado la producción inmobiliaria y el consumo de suelo, por la construcción de viviendas en tejidos discontinuos, y por la de polígonos industriales. En la última década del siglo XX se produjo un crecimiento espectacular, con 375 mil nuevos puestos de trabajo, se construyeron 345 mil nuevas viviendas $\mathrm{y}$, sobre todo, se consumieron miles de hectáreas de suelo (Marmolejo Duarte y Stallbohm, 2008). Durante el periodo 1985-2001 ha habido un cambio del modelo en la producción de viviendas en la provincia de Barcelona, con un desarrollo intensivo de tipologías de baja densidad, ampliamente difundido por todo el territorio de la provincia, en una suburbanización residencial con tipologías diferentes ${ }^{47}$.

La vivienda aislada y de mayor superficie sería accesible solo a grupos reducidos de la población, mientras que la vivienda en bloques y la vivienda adosada se construiría para una población más diversificada. Los grupos de

46 Además de Barcelona, incluye seis ciudades grandes de tamaño superior a los cien mil habitantes (Badalona, Hospitalet de Llobregat, Sabadell, Terrassa, Mataró y Santa Coloma de Gramanet), nueve ciudades de tamaño intermedio, entre 50.000 y 100.000 habitantes, 44 ciudades pequeñas muy dinámicas, de 10.000 a 50.000 habitantes, "que crecen con gran celeridad", y 61 municipios de 2.000 a 10.000 habitantes. El medio rural o, más bien, rururbanizado no es ajeno a la metrópoli barcelonesa, con 43 municipios menores de 2.000 habitantes según Pujadas, 2009. Sobre el policentrismo terciario, Marmolejo y Roca, 2008 y Pérez Prieto y Marmolejo, 2008.

47 Estudiadas por Font, Llop y Vilanova, 1999, y Font et al., 2005. 
rentas medias y bajas cambiaron sus opciones iniciales de comprar vivienda en bloques, para adquirir vivienda adosada en municipios periféricos, debido a los precios más bajos de estas viviendas y a la oferta existente. La oferta. es el factor esencial; los habitantes, en palabras de Francesc Muñoz, "acaban vinculándose a los mercados de viviendas suburbanas, donde la presencia importante de vivienda de baja densidad hace cambiar las opciones iniciales de compra de vivienda en bloque a vivienda adosada" (Muñoz, 2004).

Existen diferencias de valoración sobre los procesos de expansión, densificación y organización de la urbanización en la región metropolitana de Barcelona. Para algunos el balance es favorable, como resultado de los esfuerzos que han hecho los ayuntamientos para ordenar la planificación y la gestión de las ciudades ${ }^{48}$. Otros estudios muestran que la Región Metropolitana ha ganado densidad, y ha mejorado la conexión entre sectores antes urbanizados de forma fragmentaria, sobre todo debido a las decisiones de urbanización tomadas desde los diferentes municipios (Marmolejo Duarte y Stallbohm, 2008).

Frente a esas interpretaciones, algún autor ha insistido en que la urbanización dispersa que se produjo en las décadas de 1980 y 90 se hizo con escasa atención al espacio público y a los equipamientos, una expansión totalmente insostenible (problemas de redes, abastecimientos de agua..), realizada esencialmente al margen del planeamiento ordenado y sin recualificación del territorio, por iniciativa de propietarios, promotores y municipios, una forma de crecimiento que se aproxima a las que habían dominado en los años 1950, 1960 y 1970 (Muñoz, 2004). Ese crecimiento desordenado se ha atribuido a la carencia de órganos de gestión coordinados para el conjunto de los muncipios de la provincia de Barcelona, e incluso para el Área Metropolitana de Barcelona, y habría dado lugar a una especialización territorial y una segregación morfológica y social: algunos municipios se especializan en la producción de viviendas aisladas de gran superficie, mientras que otros lo hacen en viviendas adosadas de superficie menor, y progresivamente menor conforme avanza el tiempo; la vivienda en bloques se combina más frecuentemente con el adosado que con las viviendas nifamiliares aisladas.

En conjunto, la impresión que produce el Área Metropolitana de Barcelona es la de un acusado desorden y falta de planificación, con decisiones tomadas de forma totalmente autónoma por cada uno de los municipios en relación con sus propios intereses y estrategias, y sin voluntad de coordinación. No sabemos

48 Esta visión optimista aparece, para el periodo 1977-2000, en el libro coordinado por Font et al., 2005, donde concluyen que "el terrritorio metropolitano disfruta de mejor salud de lo que se rumoreaba"; una parte (38\%) de las 20.000 hectáreas consumidas en el periodo estaban ya con indicios de urbanización en 1977, y por otra parte la política urbanistica ha tratado de "reducir las manchas de suelo urbanizable y localizar los nuevos crecimientos en continuidad respecto a los núcleos urbanos existentes"; a pesar de ello, no se ha resuelto "la dispersión consolidada" que se había generado antes de 1980. 
si el Plan Territorial Metropolitano de Barcelona, que acaba de ser aprobado por el gobierno de la Generalitat en abril de 2010, logrará resolver los problemas que existen ${ }^{49}$.

\section{VII. ¿QUE HA FALLADO?}

Debe reconocerse que no es fácil la tarea a que se enfrentan los gobiernos municipales, que han de hacer frente a retos numerosos, sin tener en muchos casos competencias ni recursos, que deben obtener apoyos de los gobiernos autonómicos y estatal (lo que no siempre es posible cuando los colores políticos son diferentes), negociar con grupos económicos muy poderosos, establecer alianzas en una sociedad muy compleja, y dirimir en conflictos de intereses muy variados y a veces irreconciliables. Todo ello viene agravado por el rápido ritmo del cambio social, económico y tecnológico, difícilmente comprensible a veces incluso para políticos, profesionales y científicos, que tienen dudas sobre las respuestas más adecuadas para enfrentarse a él.

Pero debe esperarse de los partidos políticos claridad en sus planteamientos y consecuencia con sus ideales. Es en este sentido que deben analizarse los errores que han podido cometer los ayuntamientos de izquierdas de Barcelona, gobernados (a veces, da la impresión) por una izquierda muy confusa, como en la mayor parte de Europa, y de poco coraje para exponer y defender claramente sus ideales. Tal vez afectada, además, en España por carencias y vicios provocados por los cuarenta años de interrupción de la democracia durante el régimen político franquista. Y por la confusión que introduce en la vida política española el desarrollo de los nacionalismos, y el hecho de que hay políticos en los que parece primar más el sentimiento nacionalista que la ideología política de izquierda.

No siempre es fácil el acuerdo sobre el alcance y las consecuencias de las operaciones realizadas. No es raro que la misma iniciativa pueda tener simultáneamente una valoración positiva y negativa. Así la de ordenación del litoral norte de Barcelona para la construcción del Forum de las Culturas puede ser valorada como un esfuerzo para dignificar aquel sector del municipio, degradado por depuradoras e industrias contaminantes, o como un proceso de artificialización del litoral, de terciarización y de construcción de viviendas de lujo. De

49 El Gobierno de la Generalitat aprobó en 2010 el Plan Territorial Parcial de la Región Metropolitana de Barcelona, que ha de ordenar el desarrollo terrotiral de la region hasta 2026; este plan se ha elaborado en base a 15 criterios que establecen, entre otras, la necesidad de asegurar el crecimiento compacto de las ciudades de la RMB y evitar la dispersión. Los contenidos del PTMB se pueden consultar a través de la página web del IET $(<$ http://www.ietcat.org/index. $\mathrm{php} / \mathrm{ca} /$ plans-territorials-parcials/pla-territorial-metropolita-de-barcelona-ptmb $>$ ). Uno de los impulsores de dicho Plan, el geógrafo Oriol Nel.lo, como Secretario de Planificación Territorial del gobierno de la Generalitat, ha presentado su génesis, desarrollo y objetivos (Nel.1o, 2011, en publicación). 
manera similar, puede existir valoraciones muy opuestas sobre la iniciativa del 22@y sobre el conjunto de las transformaciones impulsadas en el Poblenou ${ }^{50}$.

Esas visiones contrapuestas tienen que ver, sin duda, con formas diferentes de concebir la ciudad. Pero pueden ser motivadas también por la manera como se han realizado dichas intervenciones, la incapacidad para dialogar sobre decisiones que afectan a pequeñas empresas y a pequeños propietarios, los cambios de calificación y expectativas o la inadecuada valoración del tejido productivo existente. Algunas estructuras industriales existentes en Barcelona, y concretamente en Poblenou, podían no ser de nuevas tecnologías, pero eran rentables y a veces innovadoras y con futuro. Parece haber existido una incapacidad para gestionar todo el proceso de forma compleja y fina.

Ha habido mucha autocomplacencia, un exceso de autosatisfacción, y a veces un despilfarro, propio de los nuevos ricos. Se atribuyó un poder desmedido a los técnicos, especialmente arquitectos. Se ensalzó y mitificó la importancia de la experiencia técnica y profesional en Barcelona, y las realizaciones de los años 1980. No se dijo que muchas iniciativas que se tomaron se adoptaban igualmente en otras ciudades españolas, y que en algunos casos eran impulsadas por las medidas legales estatales. El Estado ha ayudado con decisiones que no siempre se aprecian y valoran, y que incluyen inversiones para la construcción subterránea de la línea del AVE hasta la nueva estación de Sagrera, a instancias del Ayuntamiento, o, en 2004, el traslado a Barcelona de la sede de la Comision Nacional del Mercado de Telecomunicaciones.

Tal vez lo más grave de todo es que los políticos municipales se han negado al diálogo, han tenido miedo a la participación, han menospreciado a los movimientos populares; que, sin embargo, se opusieron a medidas equivocadas, como el plan de ascensores en la Barceloneta, reclamaron equipamientos sociales, como escuelas, guarderías o bibliotecas. Políticos del Ayuntamiento o de la Generalitat no escucharon las voces de profesionales y personas independientes que hacen críticas, y tampoco las de los vecinos.

La ausencia de diálogo ha llevado a desvalorar los movimientos ciudadanos que pretendían preservar el patrimonio histórico. Arquitectos y políticos descalificaron sus críticas y propuestas, las tildaron de conservacionismo romántico, trasnochado y desfasado, opuesto al progreso de la ciudad, a la modernidad y al desarrollo económico. No se daban cuenta de que eran esos movimientos populares los que defendían la diversidad económica, la innovación basada en lo que existe, arraigada en la tradición y en el tejido productivo. Eran los políticos y técnicos los que no eran conscientes de la riqueza del tejido productivo y social existente en el Poblenou, en las posibilidades que los espacios fabriles y los ambientes arquitectónicos existentes ofrecian para actividades innovadoras

50 La creación del distrito 22@, fue seguramente una buena iniciativa que trataba de modificar la geografía del sistema productivo local, pero ha podido ser mal gestionada (Boixader, 2007). Los problemas del cluster de nuevas tecnologías en Bosch y Capel-Tatjer, 2004. Análisis crítico del posicionamiento del 22@, como cluster respecto otros ejemplos: Bosch \& Capel, et al., 2008. 
desde el punto de vista económico, artístico y cultural. En ocasiones se pusieron en manos de las multinacionales, les ofrecieron terrenos e infraestructuras, y destruyeron espacios que podían haber atraido artistas y gentes diversas, y que se han ido a otras ciudades. No atendieron a las demandas sociales de los residentes, menospreciaron el ambiente de la Rambla del Poblenou y de otros sectores vecinos. Negociaron con los grandes propietarios y los promotores y no supieron hacerlo con los pequeños y con los vecinos.

Los grupos políticos que detentan el poder en el Ayuntamiento de Barcelona han reiterado en varias ocasiones la voluntad de facilitar la participación y conseguir un consenso social. En este sentido cabe señalar que en noviembre de 2002 se aprobaron las Normas de Participación Ciudadana para regular esta participación. Pero no han sabido convertirlas en un mecanismo eficaz de participación ${ }^{51}$.

El debate sobre la reforma de la Diagonal y la celebración de un referéndum sobre ello se planteó y desarrolló de manera incomprensible. Desde afuera se tiene la impresión de que con el referendun querían mostrar la existencia de una participación popular en las decisiones urbanísticas. El fracaso fue total y se hizo dimitir al primer teniente de alcalde, Carles Martí.

Ha sido grande la incapacidad de aceptar las críticas que se han hecho a la gestión municipal, especialmente por parte del movimiento ciudadano, que eran sus propios votantes. Ante las críticas, los responsables políticos se acostumbraron a repetir el llamado "argumentario" del partido correspondiente, sin capacidad de pensar por su cuenta, como si vieran las reivindicaciones más como amenazas que como aportaciones. Todo ello contribuyó a que las relaciones entre el Ayuntamiento y la FAVB se hicieran difíciles ${ }^{52}$.

No fueron capaces de conectar con los vecinos, y tal vez por eso hicieron concesiones excesivas de edificabilidad. No ha habido transparencia en las negociaciones con los promotores inmobiliarios, por ejemplo en la definición de las unidades de actuación. Se necesita mayor transparencia en las decisiones urbanísticas, y la publicidad en las negociaciones, la comunicación con los habitantes.

La participación y el diálogo se ha de hacer con garantías, y no como un proceso dirigido por expertos politólogos y técnicos de la comunicación. Sin duda el trámite de información pública para la realización de alegaciones a los planes está ya recogido en la normativa, y se cumple, aunque no siempre con la publicidad adecuada y los asesoramientos oportunos a los afectados. Pero se ha de buscar algo más. Se han de escuchar las voces, conocer su grado de representatividad, han de existir actas de las reuniones, se ha de dar asesoramiento jurídico a los vecinos. Las reuniones de participación no deben servir para legitimar los proyectos ya decididos.

51 Entre los trabajos que han examinado la retórica de la participación y la forma como se realiza realmente se encuentran los de Casellas, 2007, Clarós i Ferret, 2007.

52 Clarós i Ferret, 2007. Sobre los disensos que se manifestaron después de los Juegos Olímpicos, Pareja Eastway, 2010 (en este número). 
Los escandalos de corrupción que se conocían en España parecían no afectar a Cataluña, y en algún caso incluso se llegó a hablar, en este sentido, del "oasis catalán”. Una alusión explícita de Pascual Maragall como Presidente de la Generalitat a las comisiones del 3 por ciento y más pagadas por constructoras e inmobiliarias al gobierno de Convergencia i Unió para la adjudicación de obras, levantó una gran reacción nacionalista e hizo echar marcha atrás a este político y a su gobierno. Fue una buena ocasión perdida, no se sabe bien porqué. El movimiento vecinal, sin embargo, no se calló y el ministerio fiscal tampoco. Con ello la corrupción pasó a estar también presente en la escena política catalana.

En julio de 2009 provocó un gran terremoto político el descubrimiento de que un conocido miembro de la burguesía nacionalista catalana, que acababa incluso de ser honrado por el Ayuntamiento con la Medalla de Oro de Barcelona, había desviado unos 30 millones de euros desde la presidencia de la Fundación del Palau de la Música Catalana y del Orfeón Catalán, y de que, además de su enriquecimiento personal, una parte de esos fondos parecía haber servido para financiar irregulamente a Convergencia i Unió.

El caso Palau tuvo una derivación inesperada cuando se planteó también el tema de la construcción de un hotel vinculado al mismo, una operación especulativa denunciada por los vecinos y por la revista La Veu del Carrer órgano de la Federación de Asociaciones de Vecinos de Barcelona ${ }^{53}$. Se trata de un tema que ha acabado afectando asimismo al teniente de alcalde y al gerente de urbanismo del Ayuntamiento de Barcelona acusados de prevaricación, por si habían tenido noticias sobre la titularidad del hotel antes de cambiar la calificación del suelo para facilitar su construcción.

No se tienen suficientes datos sobre la imbricación entre los agentes económicos que actúan en Barcelona, las relaciones y conflictos entre los agentes locales y los internacionales, los tradicionales y los nuevos, los modos de interacción con las instituciones empresariales existentes (Cámara de Comercio, Fomento del Trabajo, Círculo Ecuestre...) y con los partidos políticos, la forma de actuar en relación con iniciativas como la puesta en marcha del 22@ ${ }^{54}$. Necesitamos más estudios del mundo de las grandes empresas, más trabajo de investigación y conocimiento de la realidad, con nuevos análisis empíricos, y nuevos marcos teóricos explicativos de la evolución y de los procesos. Se ha destruido a veces el tejido productivo, económico, con poca atención. No se ha tenido en cuenta la importancia de la diversificación, la necesidad de otras actividades, la complejidad de los espacios en los que se actúa.

Durante estos años ha habido, indudablemente, una mejora importante de las infraestructuras, en la calidad de vida. Pero también un exceso de prepotencia en las actitudes y en la morfología construida. Muchas veces el Ayuntamiento no ha sabido explicar sus objetivos, y sus realizaciones, ni solicitar y obtener $\mathrm{menu} / 2 / 4$

53 La Veu del Carrer, números 111, 113, 116 y 117, en línea, http://favb.cat/taxonomy_

54 Entre los trabajos que se van realizando, Boixader, 2007. 
ayudas, o defender las políticas y las decisiones adoptadas, con coraje y convicción. Pero más allá de ello, es todo el modelo urbano, de construcción de la ciudad, lo que está en cuestión.

Frente al que se ha seguido, se necesita otro modelo de realización del urbanismo $^{55}$. No podemos seguir creciendo indefinidamente. Los grandes agentes económicos privados actúan hoy a diferentes escalas y tienen los territorios urbanos como frentes de actuación. Tratan por ello de intervenir en la definición de las políticas urbanas y de los modelos de intevención territorial. La izquierda necesita reflexionar sobre nuevos modelos de desarrollo económico, de desarrollo urbano y de organización social.

El resultado de las elecciones al Parlamento Catalán, que se han celebrado el día 28 de noviembre, ha supuesto el fin del gobierno de izquierdas en la Comunidad Autónoma de Cataluña. El índice de abstención ha sido del 40 por ciento, y el triunfo de Convergencia i Unió indudable. En mayo de 2011 se celebrarán elecciones municipales. Tal vez sea el momento de iniciar un profundo proceso de reflexión que muestre la capacidad de la izquierda para presentar de forma coherente su modelo de ciudad, y para dirigir los cambios que es preciso introducir en la economía y en la estructura social ante los graves retos que están hoy planteados. Para lo que se necesitan nuevos comportamientos políticos, y nuevos marcos teóricos y de actuación territorial.

\section{BIBLIOGRAFÍA}

Almeida M G (2008) Novas territorialidades ou múltiplas territorialidades? Trabalhador migrante brasileiro em Barcelona. Scripta Nova. Revista Electrónica de Geografía y Ciencias Sociales, $\mathrm{XII}(270): 131$.

Andreu M (2010) La ciutat corrompuda. La Veu del Carrer. FAVB-Editorial Mediterrània, Barcelona.

Andreu M (2008) Moviments socials i crítica al 'model Barcelona'. De l'esperança democràtica de 1979 al miratge olímpic de 1992 i la impostura cultural del 2004. Scripta Nova. Revista Electrónica de Geografía y Ciencias Sociales, XII(270): 119.

Andreu M H, Josep M (1996) Barcelona en lluita (el moviment urbà 1965-1996). Barcelona: Federació d'Associacions de Veïns de Barcelona.

Andreu M, Eva F, Andrés N, Carles P (coords.) (2010) 1970-2010, 40 Anys d'acció veïnal (Col·lecció "Quaderns de Carrer", 5). Federació d'Associacions de Veïns i Veïnes de Barcelona, Barcelona.

Andreu M, Herranz E, Naya A (coords.) (2007) Carrer. 15 anys / 100 números. FAVB-Editorial Mediterrània, Barcelona.

Aramburu M (2001) El mito de la "huida" autóctona. El caso de Ciutat Vella, Barcelona. Scripta Nova. Revista Electrónica de Geografía y Ciencias Sociales. (Número extraordinario dedicado al III Coloquio Internacional de Geocrítica sobre "Migración y cambio social"), V(94): 63.

Arantes O B F (2000) Uma estratégia fatal. A cultura nas novas gestôes urbanas. In Maricato E, Vainer C, Arantes $\mathrm{O}$ (eds) A cidade do pensamento único: desmanchando consensos. Vozes, Petrópolis: 11-74. 
Arantes O B F, Carlos B V, Erminia M (2000) A cidade do pensamento único. Desmanchando consensos. Vozes, Petrópolis.

Bayona Carrasco J, Alonso G F (2008) El papel de la inmigración extranjera en la expansión de las áreas urbanas. El caso de Barcelona (1998-2007). Scripta Nova. Revista Electrónica de Geografía y Ciencias Sociales, XII(270): 161.

Bohigas O (2005) El model Barcelona segons Horacio Capel. Avui: 21 [Respuesta en Capel 2006].

Boixader J (2005) La acción colectiva de los agentes urbanos en la transformación de Barcelona. Scripta Nova. Revista electrónica de geografía y ciencias sociales, IX(194): 80.

Borja i Sebastià J (2009) Luces y sombras del urbanismo de Barcelona. Editorial UOC, Barcelona.

Borja i Sebastià J (2005) Un futuro urbano con un corazón antiguo. Biblio 3W, Revista Bibliográfica de Geografía y Ciencias Sociales, Universidad de Barcelona, X(584).

Borja i Sebastià J (ed.) (1995) Barcelona: un modelo de transformación urbana, 1980-1995. Quito: Programa de Gestion Urbana (PGU-LAC).

Borja i Sebastià J, Muxí Martínez Z (Eds.) (2004) Urbanismo en el siglo XXI: una visión crítica: Bilbao, Madrid, Valencia, Barcelona. Edicions UPC, ETSAB (Arquitext), Barcelona.

Bosch J, Tatjer L C (2004) El districte industrial de Tecnologies de la Informació i la Comunicació (TIC) a Barcelona. Comparació amb altres ciutats europees. Scripta Nova. Revista Electrónica de Geografía y Ciencias Sociales, VIII(170): 19.

Bosch J, Tatjer L C, et al. (2008) El Projecte 22@Barcelona: situació actual i comparacions internacionals. IET Documents de Treball/Workings Papers, 40.

Bosco R (2010) Entre identidad y marca. Barcelona Metrópolis, 79: 6-7.

Burgueño J (2009) Un país amb 7 territoris. Treballs de la Societat Catalana de Geografia, 67-68: 13-37.

Busquets J (2004) Barcelona. La construcción urbanística de una ciudad compacta. Ediciones del Serbal (Colección "La Estrella Polar"), Barcelona.

Caballé F (2010) Desaparece el barrio de Icària, nace la Vila Olímpica. Biblio 3W. Revista Bibliográfica de Geografía y Ciencias Sociales, XV(895): 9.

Caballé F (2003) Arquitectura y documentación: arqueología de la vivienda en el casco antiguo de Barcelona. Scripta Nova. Revista Electrónica de Geografía y Ciencias Sociales, VII(146): 003.

Capel H (2010a) Diálogo y participación para profundizar la democracia y dar nuevas perspectivas a la ordenación urbana y del territorio Discurso inaugural del XI Coloquio Internacional de Geocrítica. Scripta Nova. Revista Electrónica de Geografía y Ciencias Sociales, XIV(331): 1.

Capel H (2010b) Urbanización Generalizada, derecho a la ciudad y derecho para la ciudad. Conferencia inaugural del XI Coloquio Internacional de Geocrítica. Scripta Nova. Revista Electrónica de Geografía y Ciencias Sociales, XIV(331): 7.

Capel H (2010b) El urbanismo, la política y la economía (y viceversa). Una perspectiva comparada. Biblio 3W. Revista Bibliográfica de Geografia y Ciencias Sociales, XV(893).

Capel H (2009) Barcelona: construcciones, destrucciones y responsabilidades. Un capítulo censurado de la obra Destrucción y construcción del territorio, de Aurora Fernández Polanco, Magdalena Mora y Cristina Peñamarín (Editorial Complutense, 2008). Biblio 3W, Revista Bibliográfica de Geografia y Ciencias Sociales, XIII(819).

Capel H (2007) El debate sobre la construcción de la ciudad y el llamado "Modelo Barcelona". Scripta Nova. Revista Electrónica de Geografía y Ciencias sociales, XI(233).

Capel H (2006) De nuevo el modelo Barcelona y el debate sobre el urbanismo barcelonés. Biblio 3W. Revista Bibliográfica de Geografía y Ciencias Sociales, XI(629).

Capel H (2005) El modelo Barcelona: un examen crítico. Barcelona: Ediciones del Serbal, (versión francesa, Le modèle Barcelone. Traduit de l'espagnol par Juliette Lemerle. Paris: EconomicaAnthropos (Collection Villes), 2009).

Capel H (2002) Las políticas de atención a las necesidades de los inmigrantes extranjeros de escasos recursos. Scripta Nova. Revista Electrónica de Geografía y Ciencias Sociales, VI(117). 
Capel H (2000) Inmigrantes extranjeros en España. El derecho a la movilidad y los conflictos de la adaptación: grandes expectativas y duras realidades. Scripta Nova. Revista Electrónica de Geografia y Ciencias Sociales, 81.

Capel H (1996) Rehabilitación y uso del patrimonio histórico industrial. Documents d'Anàlisi Geogràfica, 15: 19-50.

Capel H, Linteau P-A (coord.) (1998) Barcelona-Montréal. Desarrollo urbano comparado/Développement urbain comparé. (Coloquio sobre "El desarrollo urbano de Montréal y Barcelona en la época contemporánea: estudio comparativo"). Barcelona: Publicacions Universitat de Barcelona (Colección "Geocrítica. Textos de Apoyo", n 14).

Casadevall C R (2009) Un nou mapa supramunicipal: els Governs territorials de salud. Treballs de la Societat Catalana de Geografia, 67-68: 39-60.

Casellas A (2007) Gobernabilidad, participacion ciudadana y desarrollo economico: adaptaciones locales a estrategias globales. Scripta Nova. Revista Electrónica de Geografía y Ciencias Sociales, XI(243).

Casellas A (2006) Las limitaciones del 'modelo Barcelona. Una lectura desde Urban Regime Analysis. Documents d'Anàlisis Geografica. Universitat Autònoma de Barcelona, 48: 61-81.

Casellas A, Montserrat P-B, Esteve D J (2010) Creación de imagen, visibilidad y turismo como estrategias de crecimiento económico de la ciudad. Finisterra - Revista Portuguesa de Geografia, XLV(90) (en publicación).

Castañer M, Gutiérrez O, Vicente J (2009) Mobilitat laboral, àreas de cohesió i àrees de planificació a Catalunya. Treballs de la Societat Catalana de Geografia, 67-68: 61-86.

Checa-Artasu M M (2008) Una herramienta para la planificación urbana: la documentación del patrimonio. El caso de Barcelona (España). Scripta Nova. Revista Electrónica de Geografía y Ciencias Sociales, XII(270): 141.

Checa-Artasu M M (2007) Geografías para el patrimonio industrial en España: el caso de Barcelona. Scripta Nova. Revista Electrónica de Geografía y Ciencias Sociales, XI(245): 32.

Cebollada À, Avellaneda P G (2008) Equidad social en movilidad: reflexiones en torno a los casos de Barcelona y Lima. Scripta Nova. Revista Electrónica de Geografía y Ciencias Sociales, XII(270): 47.

Cebollada À, Miralles Guasch C (2010) La movilidad en la región metorpolitana de Barcelona: entre los nuevos retos y las viejas prácticas. Finisterra - Revista Portuguesa de Geografia, XLV(90) (en publicación).

Clarós i Ferret S (2008) Parc del Centre del Poblenou, una crítica urbanística. Biblio 3W, Revista Bibliográfica de Geografía y Ciencias Sociales, XIII(805).

Clarós i Ferret S (2007) De la ciutat dels prodigis a la Barcelona social. Biblio 3W, Revista Bibliográfica de Geografía y Ciencias Sociales, XII(751).

Clarós i Ferret S, Estrada i Robles L, Tatjer i Mir M, Roca i Albert J, Vilanova i Omedas A (Grup De Patrimoni Industrial del Fòrum de la Ribera del Besòs) (2005) Proposta de pla integral de patrimoni industrial de Barcelona. Biblio 3W, Revista Bibliográfica de Geografía y Ciencias Sociales, $\mathrm{X}(581)$.

Cócola Gant A (2009) El MACBA y su función en la marca Barcelona. Ciudad y Territorio. Estudios Territoriales, XL(159): 87-102.

Cruz i Gallac H, Martí-Costa M (2010) Conflictos urbanísticos y movilizaciones ciudadanas: reflexiones desde Barcelona. Finisterra - Revista Portuguesa de Geografia, XLV(90) (en publicación).

Delgado M (2007) La ciudad mentirosa. Fraude y miserioa del 'modelo Barcelona'. Catarata, Madrid.

Delgado M (2005) Elogi del vianant. Del 'model Barcelona' a la Barcelona real. Edicions de 1984, Barcelona.

Degen M, García M (Eds.) (2008) La metaciudad: Barcelona. Transformación de una metrópolis. Anthropos, Barcelona.

Fava M (2010) Quanta, quanta merda. La Veu del Carrer, 117: 3.

Fava N (2008) Barcellona: osservazioni sulla letteratura riguardante i modelli di indirizzo dell'urbanistica negli ultimi 20 anni. Scripta Nova. Revista Electrónica de Geografía y Ciencias Sociales, XII(270): 71. 
Fiori M (2010) El impacto de la transformación urbana en la estructura residencial de Ciutat Vella. Tesis Doctoral dirigida por el Profesor Ferrán Sagarra. Universidad Politécnica de Catalunya, Escuela Técnica Superios de Arquitectura de Brcelona.

Font A, Llop C, Vilanova J M (1999) La construcción del territorio metropolitano. Morfogénessi de la región urbana de Barcelona. Área Metropolitana de Barcelona, Barcelona.

Font A, et al. (2005) Transformacions urbanitzadores 1977-2000. Àrea Metropolitana i Regió Urbana de Barcelona. Mancomunitat de Muncipis del Area Metropolitana de Barcelona, Barcelona.

Font A, Vecslir L (2008) Nuevas geografías de la producción y el consumo en la Región Metropolitana de Barcelona. Scripta Nova. Revista Electrónica de Geografía y Ciencias Sociales, XII(270): 107.

Ganau J, Mallarach J (2003) La planificació estratègica territorial a Catalunya. Generalitat de Catalunya, Barcelona.

García Ramón Ma D, Albet A (2000) Pre-Olympic and post-Olympic Barcelona, a 'model' for urban regeneration today? Environment and Planning A, 32: 1331-1334.

González F (2010) ¿Cómo garantizar las pensiones? El País, 25 de octubre: 29.

GRUP DE PATRIMONI INDUSTRIAL DEL FÒRUM RIBERA BESÒS (2005) Proposta de Pla Integral de Patrimoni Industrial de Barcelona. Biblio 3W. Revista Bibliográfica de Geografía y Ciencias Sociales, X(581).

Heeren S von (2002) La remodelación de la Ciutat Vella. Un análisis crítico del modelo de Barcelona. Barcelona: Prólogo de Manuel Vázquez Montalbán.

Ibarra M E (2010) Nuñez, el cosntructor que cambiaba cromos. La Veu del Carrer, 117: 4.

Limonad E (2007) No todo acaba en Los Angeles ¿un nuevo paradigma: entre la urbanización concentrada y dispersa? Biblio3W Revista Bibliográfica de Geografía y Ciencias Sociales, XII(734).

Limonad E (2006) Paris em chamas: arquitetura ou revolução? Biblio 3W, Revista Bibliográfica de Geografía y Ciencias Sociales, XI(644).

Limonad E (2005) Estranhos no paraíso de Barcelona. Impressões de uma geógrafa e arquiteta brasileira residente em Barcelona. Biblio 3W, Revista Bibliográfica de Geografía y Ciencias Sociales. X(610).

López de Lucio R (ed.) (1999) Madrid 1979-1999. La transformación de la ciudad en veinte años de ayuntamientos democráticos. Gerencia Municipal de Urbanismo y Ayuntamiento de Madrid, Madrid.

López Gay A, Recaño Valverde J (2008) La renovación sociodemográfica de un centro urbano maduro: perfiles migratorios y filtros residenciales en la ciudad de Barcelona. Scripta Nova. Revista Electrónica de Geografía y Ciencias Sociales, XII(270): 130.

López Sánchez P (1993) Todos, mayoria y minorias en la Barcelona Olímpica. Apuntes sobre el gobierno de lo social en la ciudad-empresa. Economía y Sociedad, 9: 103-115.

López Sánchez P (1991) 1992, Objetiu de tots? Ciutat-empresa i dualitat social a la Barcelona olímpica. Revista Catalana de Geografía, VI(15): 91-99.

López Sánchez P (1986) El centro histórico, un lugar para el conflicto. Universidad de Barcelona / Ayuntamiento de Barcelona, Barcelona.

Magrinyá Torner F, Gutierrez G M (2001) Inmigracion y huecos en el centro histórico de Barcelona (1986-2000), Scripta Nova. Revista Electrónica de Geografía y Ciencias Sociales, 94(62).

Marmolejo C, Roca J (2008) La localización intrametropolitana de las actividades de la información: un análisis para la Región Metropolitana de Barcelona 1991-2001. Scripta Nova. Revista Electrónica de Geografía y Ciencias sociales, XII(268).

Marmolejo C, Stallbohm M (2008) En contra de la ciudad fragmentada: ¿hacia un cambio de paradigma urbanístico en la Región Metropolitana de Barcelona? Scripta Nova. Revista Electrónica de Geografía y Ciencias Sociales, XII(270): 65.

Marshall T (2004) Transforming Barcelona. Routledge, London.

Marshall T (2000) Urban planning and governance; is there a Barcelona model? International Planning Studies, 5(3) 299-319.

Martori J C, Hoberg K (2004) Indicadores cuantitativos de segregación residencial. El caso de la población inmigrante en Barcelona. Scripta Nova. Revista Electrónica de Geografía y Ciencias Ssociales, VIII(169). 
Mendizàbal Riera E (2009) L'organització administrativa de Catalunya, un problema irresoluble. Treballs de la Societat Catalana de Geografia, 67-68: 87-109.

Miralles-Guasch C, Cebollada Á, Requena R (2010) Estrategias de participación ciudadana en la gestión de la movilidad y el transporte. La Universidad Autónoma de Barcelona como ejemplo. Scripta Nova. Revista Electrónica de Geografía y Ciencias Sociales, XIV(331): 39.

Monclús F-J (2003) El "Modelo Barcelona"¿Una fórmula original? De la "reconstrucción" a los proyectos urbanos estratégicos (1979-2004). Perspectivas Urbanas /Urban Perspectives, 3: $1-13$.

Monclús F-J (1998) Planeamiento y crecimiento suburbano en Barcelona: de las extensiones periféricas a la dispersión metropolitana (1897-1997). In Capel H, Linteau P-A (dir.) BarcelonaMontreal: desarrollo urbano comparado = développement urbain comparé: 83-96.

Montaner J M (2004a) Aregumentos de la Barcelona poliédrica. In Costa G (ed.) Barcelona 19922004. Barcelona: Gustavo Gili: 19-23.

Montaner J M (2004b) La evolución del modelo Barcelona (1979-2002). In Borja M (eds.): 203-219.

Montaner J M (2003) Repensar Barcelona. Edicions UPC, Barcelona.

Muñoz F (2008) UrBANALización: paisajes comunes, lugares globales. Editorial Gustavo Gili, Barcelona.

Muñoz F (2004) UrBANALització. La producció residencial de baixa densitat a la provincia de Barcelona, 1985-2001. Tesi Doctoral dirigida pel Drs. Ignasi de Solá-Morales i Rosa Ascón, Departament de Geografia, Universitat Autònoma de Barcelona, (Recensión en Biblio 3W, $\left.\mathrm{n}^{\circ} 528,2004\right)$

Nel-Lo O (2011) La ordenación de las dinámicas metropolitanas- El Plan Territorial Metropolitano de Barcelona. Scripta Nova. Revista Electrónica de Geografía y Ciencias Sociales. Barcelona: Universidad de Barcelona, XV (en publicación).

$\mathrm{Nel} \cdot \mathrm{Lo} \mathrm{O}$ (2009) La incerta reforma de l'organització territorial de Catalunya d'ençà l'aprovació de l'Estatut d'Autonomía de 2006. Treballs de la Societat Catalana de Geografia, 67-68: 11-152.

Oliveira F J G (2010) Área metropolitana de Barcelona: política territorial e escalas de planejamento - uma visão a partir da imprensa local. Biblio 3W. Revista Bibliográfica de Geografía y Ciencias Sociales, XV(870).

Oliveira F J G, Capel H, Barbosa J L, Zaar M H (Coords. Eds) (2010) Barcelona 1992 - Rio de Janeiro 2016: Juegos Olímpicos y movimientos populares. Número extraordinario. Biblio $3 \mathrm{~W}$. Revista Bibliográfica de Geografía y Ciencias Sociales, XV(895).

Oliveras Samitier J (2009) Reflexions sobre l'organitzacio territorial a Catalunya. Treballs de la Societat Catalana de Geografia, 67-68: 179-118.

Pareja-Eastway M (2010) Construyendo la Barcelona creativa: nuevos actores, nuevas estrategias. Finisterra - Revista Portuguesa de Geografia, XLV(90) (en publicación).

Pérez Prieto C, Marmolejo Duarte C (2008) La localización intrametropolitana de las actividades de la innovación: un análisis para la Región Metropolitana de Barcelona. Scripta Nova. Revista Electrónica de Geografía y Ciencias Sociales, XII(270): 153.

Pujadas I (2009) Movilidad residencial y expansión urbana en la Región Metropolitana de Barcelona, 1982-2005. Scripta Nova. Revista Electrónica de Geografía y Ciencias sociales, XIII(290).

Quaglieri A, Antonio P R (2010) Paisajes urbanos en la época post-turística. Propuesta de un marco analítico. Scripta Nova. Revista Electrónica de Geografía y Ciencias Sociales. XIV(323).

Queirós M (2010) Barcelona (s) Cidade dos projectos ou projectos de cidade? Finisterra - Revista Portuguesa de Geografia, XLV(90) (en publicación).

Queirós, M (2009) Impressões de uma geógrafa portuguesa sobre as transformações recentes de Barcelona. Resposta ao desafio de Horacio Capel. Biblio 3W. Revista Bibliográfica de Geografía y Ciencias Sociales, XV(850).

Resina J R (2008) La vocació de modernitat de Barcelona. Auge i declivi d'una imatge urbana. Galaxia Gutenberg, Barcelona.

Russo A P, Laura C-T (2007) From citadels of education to cartier latins (and back?): the changing landscapes of student populations in european cities. Geography Compass, 1/5: 1160-1189.

Sánchez J-E (2007) Pautas de localización de las sedes de las grandes empresas y entornos metropolitanos. Eure, XXXIII(100): 69-90. 
Sánchez J-E (1998a) Efectos de los cambios en el sistema productivo sobre la expansión metropolitana de Barcelona. In Capel H, Linteau P A (coords.): 39-50.

Sánchez J-E (1998b) Barcelona. Transformaciones en los sistemas productivos y expansión metropolitana. In Monclús F J (ed.) La ciudad dispersa. Barcelona: Centre de Cultura Contemporània de Barcelona: 59-81.

Sánchez J-E (1996) Barcelona: transformaciones en los sistemas productivos y expansión metropolitana. In Suburbanización y nuevas periferias: perspectivas urbanísticas. Barcelona: Centre de Cultura Contemporània de Barcelona.

Sánchez J-E (1992) Societal responses to changes in the production system: the case of metropolitan region of Barcelona. Urban Studies, 29(6): 949-964.

Sanclimens Solervicens X (2009) Els treballs de la Comissió d'Organització Territorial de Catalunya (2004-2006). Treballs de la Societat Catalana de Geografia, 67-68: 231-248.

Sargatal Bataller M A (2009) El barrio del Raval de Barcelona (1999-2008). Transformaciones urbanas y nuevos enfoques metodológicos para el estudio del centro histórico. Biblio $3 \mathrm{~W}$, Revista Bibliográfica de Geografía y Ciencias Sociales, Universidad de Barcelona, XIV(824).

Sargatal Bataller M A (2003) La vivienda en el centro histórico de Barcelona. El caso de la Rambla del Raval. Scripta Nova. Revista Electrónica de Geografia y Ciencias Sociales. VII(146): 069.

Sargatal Bataller M A (2002) La ocupación laboral en el centro histórico de Barcelona: los residentes de la calle de la Cera. Scripta Nova. Revista Electrónica de Geografia y Ciencias Sociales, VI(119): 52.

Sargatal Bataller M A (2001) Gentrificación e inmigración en los centros históricos: el caso del barrio del Raval en Barcelona. Scripta Nova. Revista Electrónica de Geografía y Ciencias Sociales. 94 (66).

Sargatal Bataller M A (2000) El estudio de la gentrificación. Biblio3w. Revista Bibliográfica de Geografía y Ciencias Sociales, 228.

Sastre Fulcará N (2009) Reinventar la matròpoli: Barcelona I el model de la Greater London Authority. Treballs de la Societat Catalana de Geografia. 67-68: 249-271.

Tabakman E (2001) El casc antic de Barcelona: actuación urbanística o "limpieza social"? Scripta Nova. Revista Electrónica de Geografía y Ciencias Sociales. Universidad de Barcelona, 94 (64).

Tatjer M (2008) Diez años de estudios sobre el patrimonio industrial de Barcelona. Scripta Nova. Revista Electrónica de Geografía y Ciencias Sociales, XII(270): 140.

Tatjer M (2005) Fontseré a Can Ricart. La fàbrica de Can Ricart i l'actuació de Josep Fontseré i Mestre. Biblio 3W, Revista Bibliográfica de Geografía y Ciencias Sociales, X(607).

Tatjer M, Josep O B (2005) (1811-1860) i la seva aportació a la ciència, la tècnica i l'arquitectura del segle XIX. Biblio 3W, Revista Bibliográfica de Geografía y Ciencias Sociales, X(582).

Tatjer M, Urbiola D M, Grup de Patrimoni Industrial (2005) Can Ricart Estudi Patrimonial (Síntesi). Biblio 3W, Revista Bibliográfica de Geografia y Ciencias Sociales, X(598) 30.

Ter-Minassian H (2010) La réhabilitation du centre ancien de Barcelone : discours et représentations par les pouvoirs publics (1980-2008). Espaces et Societés, 142: 97-112.

Ter-Minassian H (2009a) Y a-t-il une gentrification à Barcelone? Le district Ciutat Vella entre 1991 et 2005. Géocarrefour, 84(1-2): 93-103.

Ter-Minassian H (2009b) Ciutat Vella entre réhabilitation et gentrification. Politiques publiques et changement sociaux dans le centre ancien de Barcelona (1980-2008). Thése de Doctorat en Géographie, Université de Paris I-Panthéon-Sorbonne, et Université de Barcelona.

Ter-Minassian H (2007) Le paysage de la gentrification à Barcelone. Strates. Matériaux pour la Recherche en Sciences Sociales: paysage urbain: genèse, représentations, enjeux contemporains, $\mathrm{n}^{\mathrm{o}} 13$.

Vainer C B (2000) Pátria, empresa e mercadoria. Notas sobre a estratégia discursiva do Planejamento Estratégico Urbano. In Arantes O, Vainer C, Maricato E (eds) A cidade do pensamento único: desmanchando consensos. Vozes, Petrópolis: 75-104. 